OPEN ACCESS

Edited by:

Abhay Satoskar

The Ohio State University,

United States

Reviewed by:

Sanjai Kumar - Kumar,

United States Food and Drug

Administration, United States Herbert Leonel de Matos Guedes,

Federal University of Rio de

Janeiro, Brazil

*Correspondence:

Grégoire Lauvau

gregoire.lauvau@einsteinmed.org

${ }^{\dagger}$ These authors have contributed equally to this work

Specialty section:

This article was submitted to Microbial Immunology, a section of the journal

Frontiers in Immunology

Received: 26 June 2020 Accepted: 03 December 2020 Published: 14 January 2021

Citation:

Furtado R, Chorro L, Zimmerman N,

Guillen E, Spaulding E, Chin SS,

Daily JP and Lauvau G (2021)

Blockade of LAG-3 in PD-L1-Deficient

Mice Enhances Clearance of Blood

Stage Malaria Independent

of Humoral Responses.

Front. Immunol. 11:576743.

doi: 10.3389/fimmu.2020.576743

\section{Blockade of LAG-3 in PD-L1- Deficient Mice Enhances Clearance of Blood Stage Malaria Independent of Humoral Responses}

\author{
Raquel Furtado ${ }^{1+}$, Laurent Chorro ${ }^{1+}$, Natalie Zimmerman ${ }^{1}$, Erik Guillen ${ }^{1}$, \\ Emily Spaulding ${ }^{1}$, Shu Shien Chin ${ }^{1}$, Johanna P. Daily ${ }^{1,2}$ and Grégoire Lauvau ${ }^{1 *}$ \\ ${ }^{1}$ Department of Microbiology and Immunology, Albert Einstein College of Medicine, Bronx, NY, United States, ${ }^{2}$ Department \\ of Medicine, Albert Einstein College of Medicine, Bronx, NY, United States
}

T cells expressing high levels of inhibitory receptors such as PD-1 and LAG-3 are a hallmark of chronic infections and cancer. Checkpoint blockade therapies targeting these receptors have been largely validated as promising strategies to restore exhausted $T$ cell functions and clearance of chronic infections and tumors. The inability to develop longterm natural immunity in malaria-infected patients has been proposed to be at least partially accounted for by sustained expression of high levels of inhibitory receptors on $T$ and $B$ lymphocytes. While blockade or lack of PD-1/PD-L1 and/or LAG-3 was reported to promote better clearance of Plasmodium parasites in various mouse models, how exactly blockade of these pathways contributes to enhanced protection is not known. Herein, using the mouse model of non-lethal $P$. yoelii (Py) infection, we reveal that the kinetics of blood parasitemia as well as $\mathrm{CD}^{+}{ }^{+} \mathrm{T}$ follicular helper $\left(\mathrm{T}_{\mathrm{FH}}\right)$ and germinal center (GC) B cell responses are indistinguishable between $\mathrm{PD}-1^{-/-}, \mathrm{PD}-\mathrm{L} 1^{-/-}$and $\mathrm{WT}$ mice. Yet, we also report that monoclonal antibody $(\mathrm{mAb})$ blockade of $\mathrm{LAG}-3$ in $\mathrm{PD}-\mathrm{L} 1^{-/-}$mice promotes accelerated control of blood parasite growth and clearance, consistent with prior therapeutic blockade experiments. However, neither $\mathrm{CD}^{+} \mathrm{T}_{\mathrm{FH}}$ and $\mathrm{GC} \mathrm{B}$ cell responses, nor parasite-specific Ab serum titers and capacity to transfer protection differed. We also found that i) the majority of $L A G-3^{+}$cells are T cells, ii) selective depletion of $\mathrm{CD} 4^{+}$but not $\mathrm{CD} 8^{+} \mathrm{T}$ cells prevents anti-LAG-3-mediated protection, and iii) production of effector cytokines by $\mathrm{CD}^{+} \mathrm{T}$ cells is increased in anti-LAG-3-treated versus control mice. Thus, taken together, these results are consistent with a model in which blockade and/or deficiency of PD-L1 and LAG-3 on parasite-specific CD4 ${ }^{+} T$ cells unleashes their ability to effectively clear blood parasites, independently from humoral responses.

Keywords: checkpoint therapeutic blockade, PD-1/PD-L1/LAG-3, inhibitory receptors, malaria, humoral immunity, LAG-3+ CD4+ and CD8+ T cells, PD-L1 and PD-1 knockout mice, Plasmodium yoelii 


\section{INTRODUCTION}

The remarkable success of anti-cancer checkpoint blockade therapies have provided formal proof of concept that reinvigorating $\mathrm{T}$ cells with their effector potential is a feasible and realistic approach to achieve more effective immune-based therapies of human diseases (1). Understanding signals that can modulate and shape $\mathrm{T}$ cell functions has established the importance of costimulatory and coinhibitory pathways in $\mathrm{T}$ cell biology (2). While co-stimulation is essential to prime fully functional $\mathrm{T}$ cells, expression of inhibitory receptors such as program cell death 1 (PD-1) and Lymphocyte Activation Gene 3 (LAG-3) (3) expressed on activated T cells, enables regulation and optimal memory formation. Expression of PD- 1 facilitates the down regulation of activated $\mathrm{T}$ cell functions through interactions with its major ligands PD-L1 and PD-L2. LAG-3 is a CD4 homolog that binds MHC class II on antigen-presenting cells with higher affinity than $\mathrm{CD} 4$ and can act as a negative regulator of $\mathrm{T}$ cell functions. Recently, the fibrinogen like protein 1 (FGL-1) that is naturally expressed by liver cells and overexpressed by some tumor cells, was also characterized as a new ligand for LAG3 which can potently prevent $\mathrm{T}$ cell activation upon binding (4).

In the context of chronic viral infections (HIV, Hepatitis C) and in tumors, sustained antigenic stimulation and an immunosuppressive microenvironment promote the onset of $\mathrm{T}$ cells that maintain high levels of PD-1 and LAG-3 and exhibit an "exhausted" or dysfunctional phenotype, which prevents robust host protective effector $\mathrm{T}$ cell responses $(1,5)$. Blockade of the PD-1/PD-L1 pathway can -at least partially- rescue $\mathrm{T}$ cell functionality and allow for virus and tumor clearance (6). The fundamental importance of targeting $\mathrm{T}$ cell inhibitory pathways for therapeutic purposes has been highlighted in various cancers (1). More recently, several reports have also provided strong evidence that these inhibitory pathways may account for the lack of long-term sterilizing immunity in malaria-infected patients (7). Expression of high levels of PD- 1 and LAG-3 on $\mathrm{CD}^{+}{ }^{+}$and $\mathrm{CD} 8^{+} \mathrm{T}$ cells, and expansion of such cells among peripheral blood mononuclear cells (PBMCs) of malaria-infected patients has been reported $(8,9)$. In addition, transcripts encoding the butyrophilin family member butyrophilin-like 2 (BTNL2), another negative regulator of T-cell activation, were increased during malaria infection compared to convalescent uninfected controls (10). Likewise, a subset of "atypical" memory B cells (CD21 $\left.{ }^{-} \mathrm{CD} 27^{-} \mathrm{CD} 10^{-}\right)$, originally described as "exhausted" B cells in HIV- and HCV-infected patients $(11,12)$, are expanded in malaria patients and may contribute to the lack of effective long-lived immunity against this parasite $(9,11)$. Both PD-1 and LAG-3 inhibitory molecules are also upregulated in various surrogate non-lethal mouse models of blood stage malaria $(8,12,13)$, and, as in chronic viral infections and tumors, their selective blockade accelerates pathogen elimination. While enhanced parasite clearance is accounted for by improved $\mathrm{CD}^{+} \mathrm{T}$ and $\mathrm{B}$ cell/antibody responses (8), other mechanisms involving the restoration of $\mathrm{CD}^{+} \mathrm{T}$ cell cytolytic functions are also proposed (13).

Because of the potential clinical significance of these inhibitory pathways during malaria infection, we investigated the relative contribution of PD-1/PD-L1, LAG-3 or both pathways in the clearance of Plasmodium parasites from the blood of infected mice, and the modulation of host immune responses to improve infection outcomes. Using the non-lethal and non-chronic P. yoelii (17XNL1.1) mouse model of blood stage malaria infection, we report that mice genetically deficient for PD-L1 and PD-1 exhibit comparable kinetics of blood parasitemia to WT counterparts. We also found that LAG-3 blockade in PD- $\mathrm{L}^{-1-}$ mice accelerates parasite clearance as in WT mice co-treated with anti-LAG-3/ PD-L1 monoclonal Abs (mAbs). Yet, while therapeutic blockade of PD-L1/LAG-3 in WT mice promotes a greater magnitude of $\mathrm{CD}^{+} \mathrm{T}_{\mathrm{FH}}$ and $\mathrm{GC} \mathrm{B}$ cell responses, that of LAG-3 in PD- $\mathrm{L1}^{-1-}$ mice fails to enhance these responses. Rather, we reveal that blockade of LAG-3, which is mostly detected on activated $\mathrm{CD}^{+}$and $\mathrm{CD} 8^{+} \mathrm{T}$ cells, promotes parasite clearance independent of parasite-specific $\mathrm{Abs}$ and $\mathrm{CD} 8^{+} \mathrm{T}$ cell responses. Since $\mathrm{CD} 4^{+} \mathrm{T}$ cells are required for blood parasite elimination, these results are consistent with a model in which blockade of LAG-3 and PD-L1 act synergistically on $\mathrm{CD} 4^{+}$ $\mathrm{T}$ cells to mediate direct parasite clearance.

\section{MATERIALS AND METHODS}

\section{Mice}

This study was carried out in strict accordance with the recommendations by the animal use committee at the Albert Einstein College of Medicine that approved the animal protocol.

Wild-type (WT) C57BL/6J (B6) 6-12 week-old male mice, PD- $1^{-/}$and ${\mathrm{PD}-\mathrm{L} 1^{-1}}^{-1}$ (Gift Stan Nathenson, Einstein) were housed and bred in our SPF animal facility for all experiments.

\section{Plasmodium Infections, Blood Parasitemia, and Adoptive Serum Transfers \\ Infections}

Plasmodium yoelii (Py) 17XNL(1.1) parasites (stock MRA-593) and GFP expressing parasites (stock MRA-817) were obtained from the Malaria Research and Reference Reagent Resource Center as part of the BEI Resources Repository (NIAID, NIH, Manassas, VA. The P. yoelii, strain 17XNL(1.1), MRA-593 was contributed by D. J. Carucci. $P$-infected red blood cells (iRBC) from a frozen stock $\left(-80^{\circ} \mathrm{C}\right.$ in Alsever's solution, $10 \%$ glycerol $)$ were intraperitoneally (i.p.) injected into a WT B6 mouse and grown for $\sim 4$ days. When parasitemia reached $2 \%-5 \%, 2 \times 10^{5} P y$ iRBCs were injected intravenously (i.v.) into each experimental mouse.

\section{Parasitemia and Weight}

Blood parasitemia was determined by flow cytometry on $1 \mu$ of blood obtained by cutting the tip of the mouse tail with a sterile razor. Blood was fixed in $200 \mu \mathrm{l}$ of $0.025 \%$ glutaraldehyde in PBS $1 \mathrm{mM}$ EDTA before washing and permeabilization with $0.25 \%$ Triton X-100 in PBS for 5 min. After centrifugation, RBCs were incubated in $1 \mathrm{mg} / \mathrm{ml}$ RNAse A (Sigma) for $30 \mathrm{~min}$ at room temperature (RT) and stained with $0.5 \mu \mathrm{M}$ of the YOYO- 1 dye (Invitrogen) for $30 \mathrm{~min}$ at $\mathrm{RT}$ and directly analyzed on a $\mathrm{BD}$ FACSCanto II (Becton Dickinson, CA). RBCs were gated based on forward and side scatter, and parasitemia was determined as the 
frequency of YOYO $-1^{+}$cells among all gated RBCs. Manual counting of Giemsa-stained blood smears by microscopy gave comparable parasitemia results. Mice were individually weighed (recorded in grams) on a tared weighing scale prior to blood collection.

\section{Serum Transfer Experiments}

Serum harvested from blood collected by cardiac puncture from indicated mice, at indicated time points was stored at $-80^{\circ} \mathrm{C}$. Serum was thawed, pooled within treatment groups and $150 \mu \mathrm{l}$ of pooled serum were transferred to experimental mice intravenously (i.v.) prior to infection with $P$. yoelii $17 X N L(1.1)$. Pooled serum was heat inactivated at $56^{\circ} \mathrm{C}$ for $30 \mathrm{~min}$ prior to use in ELISAs.

\section{Antibody Blockade and Depletion PD-L1, PD-1, and LAG-3 Blockade}

$200 \mu \mathrm{g}$, unless otherwise indicated in figure legends, of polyclonal rat IgG (BioXcell; isotype) or anti-LAG-3 (clone C9B7W, BioXcell) and/or anti-PD-L1 (10F.9G2, BioXcell) or anti-PD-1 (RMP1-14, BioXcell) blocking Abs were injected i.v. into bloodstage parasitized mice beginning on day 9 or 12 after infection (as indicated) and every 3 days until day 15 or 18 as indicated. Antibodies which contained endotoxin levels above $3 \mathrm{EU} / \mathrm{ml}$ (Kinetic-QCL Kinetic Chromogenic LAL Assay, Lonza) were depleted of endotoxin with the ToxinEraser Endotoxin Removal kit (GenScript) following manufacturer's instructions.

\section{T Cell Depletions}

$150 \mu \mathrm{g}$ of anti-CD4 (clone GK1.5) or anti-CD8 $\beta$ (H35) mAbs were injected intraperitoneally (i.p.) one day before $P$. yoelii $17 X N L(1.1)$ infection, and then at day 4 and 9 post infection.

\section{Preparation of Cell Suspensions for Flow- Cytometry (FACS) Analysis}

Spleens were dissociated on nylon meshes $(100 \mu \mathrm{m})$ and incubated at $37^{\circ} \mathrm{C}$ for $20 \mathrm{~min}$ in HBSS medium containing $4,000 \mathrm{U} / \mathrm{ml}$ of collagenase I (Gibco) and $0.1 \mathrm{mg} / \mathrm{ml}$ of DNase I (Roche), and RBCs further lysed with $0.83 \% \mathrm{NH}_{4} \mathrm{Cl}$ buffer. Cells were resuspended in FACS buffer (PBS 1\% FCS, 2mM EDTA, $0.02 \%$ sodium azide) and used for the different analyses detailed below.

\section{Cell Staining for FACS Analysis}

Cell suspensions were incubated with $2.4 \mathrm{G} 2$ antibody for $15 \mathrm{~min}$ at $4^{\circ} \mathrm{C}$ and further stained with various antibody cocktails (Supplementary Table 1) in FACS buffer. For detection of intracellular IFN $\gamma, \mathrm{TFN} \alpha$ and IL-2 staining, cells were incubated for $3-4 \mathrm{~h}$ at $37^{\circ} \mathrm{C}, 5 \% \mathrm{CO}_{2}$ in RPMI 1640 (Invitrogen) 5\% FCS, Golgi Plug (BD, 1/1,000), Golgi Stop (BD, 1/1,000), PMA (Fisher, $50 \mathrm{ng} / \mathrm{ml}$ ), Ionomycin (Fisher, $1 \mu \mathrm{g} / \mathrm{ml}$ ) and then fixed in IC fixation buffer (eBioscience) for $15 \mathrm{~min}$ at $4^{\circ} \mathrm{C}$, and permeabilized for $30 \mathrm{~min}$ in $1 \mathrm{X}$ Perm/Wash buffer (eBioscience) containing indicated intracellular marker(s). For detection of transcription factors (BCL6, EOMES, FoxP3, $\mathrm{T}_{\text {bet }}$, TCF1), Ki67 and Granzyme $B$, cells were fixed and permeabilized after the surface stain with the FoxP3/Transcription Factor Staining Buffer Set following the manufacturer's instructions (eBioscience). Stained cells were collected on BD LSR-II or Aria III and the Cytek Aurora. Data were analyzed using FlowJo version 9.6.6 or FlowJo version 10.5.3 (TriStar).

\section{ELISA for Parasite Antigens}

Detection of antibodies against P. yoelii $\mathrm{MSP}_{19}$ (BEI resources/ ATCC, MRA-48) in mouse sera collected at indicated time points, were done by ELISA following an adapted protocol (8). Briefly, sera dilutions were incubated for $1.5 \mathrm{~h}$ at $37^{\circ} \mathrm{C}$ in high bind polystyrene microplate wells (Corning) that were first blocked with $1 \%$ BSA and then coated with MSP1 $_{19}(2.5 \mu \mathrm{g} /$ $\mathrm{ml})$. Total specific IgG sera antibodies were detected with horse radish peroxidase (HRP) conjugated goat anti-mouse IgG antibodies (Jackson ImmunoResearch) followed by addition of the substrate 3,3',5,5'-tetramethylbenzidine (Sigma) and reading of absorbance at $450 \mathrm{~nm}$. Endpoint titers were reported with the background absorbance of PBS coated wells subtracted.

\section{Statistics}

Statistical significance was calculated using an unpaired Student $t$ test with GraphPad Prism software and two-tailed P values are reported as: $\left(^{*}\right) \mathrm{P}<0.05,\left({ }^{* *}\right) \mathrm{P}<0.01,\left({ }^{* * *}\right) \mathrm{P}<0.001,\left({ }^{* * *}\right)$ $\mathrm{P}<0.0001$, (ns) $\mathrm{P}>0.1$. All $\mathrm{p}$ values of 0.05 or less were considered significant and are referred to as such in the text.

\section{RESULTS}

\section{While Blockade of LAG-3 and PD-L1 Synergize to Enhance the Control of Blood Parasitemia, Genetic Lack of PD-1 and PD-L1 Are Compensated}

Overexpression of inhibitory molecules such as PD-1, LAG-3, or BTNL-2 on antigen-experienced T cells in malaria-infected patients were suggested as possible mechanisms accounting for the impaired development of effective and long-lasting adaptive immunity $(7,8$, 10). Consistent with this idea, therapeutic co-blockade of PD-L1 and LAG-3 inhibitory molecules in WT mice was reported to act synergistically to decrease blood parasite growth and accelerate its clearance (8). Based on these results, we hypothesized that mice lacking the PD-1/PD-L1 inhibitory pathway should control parasite growth and clearance faster than WT counterparts. We also postulated that the therapeutic blockade of LAG-3 in PD-L1 ${ }^{-1}$ mice should phenocopy that of PD-L1/LAG-3 co-blockade in WT mice. To test these possibilities, we first inoculated mice genetically deficient for the genes encoding PD-1 or PD-L1 (PD1 ${ }^{-/-}, \mathrm{PD}-\mathrm{L1}^{-/-}$, namely $\mathrm{KO}$ ) and their littermate controls, which possess only one functional copy of either gene $\left(\mathrm{PD}^{+/-}, \mathrm{PD}-\mathrm{L} 1^{+/-}\right.$, namely heterozygotes) or both copies $\left(\mathrm{PD}^{+/+}, \mathrm{PD}-\mathrm{L1}^{+/+}\right.$, namely WT), with red blood cells (RBCs) infected with the non-lethal strain of Plasmodium, P. yoelii 17XNL (Py) (Figure 1A). Contrary to expectations, the kinetics of $P y$ growth and elimination was similar between all these groups, suggesting the existence of compensatory mechanisms making $\mathrm{PD}^{-/-}$and $\mathrm{PD}-\mathrm{L1}^{-/-}$mice as resistant to $P y$ infection as WT mice. We next injected WT and PD$\mathrm{L1}^{-/-}$mice with anti-LAG-3 and anti-LAG-3/PD-L1 or anti-LAG-3/ PD-1 mAbs, respectively (Figure 1B). LAG-3 blockade in PD-L1 ${ }^{-1}$ 

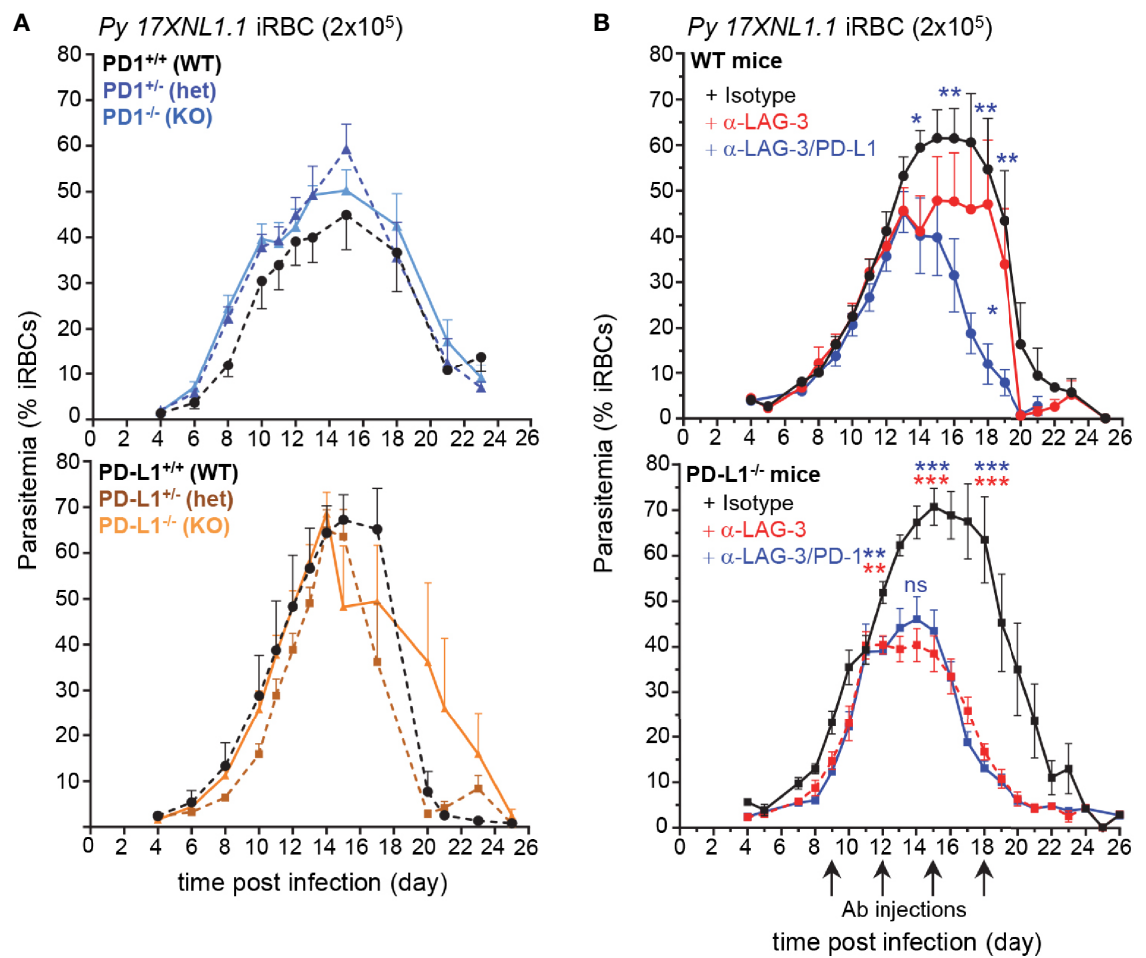

FIGURE 1 | Lymphocyte Activation Gene 3 (LAG-3) and PD-L1 blockade enhances blood parasite clearance, yet PD-1-/- and PD-L1-/- mice clear parasite like WT mice. (A) Littermates of indicated genotypes were inoculated with $2 \times 10^{5}$ Py $17 X N L 1.1$ iRBC i.v. Blood parasitemia was measured starting 4 days post infection and every other day until day 24-26 using YOYO-1 staining of RBC and FACS. PD1 ${ }^{+/+}(n=5), P D 1^{+/-}(n=5), P D 1^{-/-}(n=5), P D-L 1^{+/+}(n=3), P D-L 1^{+/-}(n=5), P D-L 1^{-/-}(n=4)$ (B) WT or PD-L1 $1^{-/-}$mice were inoculated with $2 \times 10^{5} \mathrm{Py}$ iRBC i.v., and 9, 12, 15, and 18 days post infection, indicated mice received $200 \mu \mathrm{g}$ of either anti-LAG-3 (WT n=13, PD-L1 ${ }^{-/-} n=12$ ), anti-LAG-3/PD-L1(WT $n=12$ ), anti-LAG-3/PD-1 (PD-L1/- $n=10$ ) or polyclonal rat lgG Ab (isotype, WT $n=12$, PD-L1 ${ }^{-/-} n=12$ ) i.v. Results show the kinetics of blood parasitemia over time determined by YOYO-1 staining of RBC collected at indicated time points. Graphs average the pool of two to three independent experiments $(n=10-13)$ shown with SEM. P-values are indicated when applicable $\left({ }^{*} p<0.05\right.$, ${ }^{* *} p<0.01$, $\left.{ }^{* \star *} p<0.001\right)$ for each treatment compared to isotype (asterisk color indicate respective treatment group) or to anti-LAG-3 treatment per time point (middle blue asterisk or "ns" on graphs for anti-LAG-3/PD-L1 compared to anti-LAG3) by student's t-test.

mice promoted reduced parasitemia to an extent that was comparable to that of WT mice treated with anti-PD-L1/LAG-3 mAbs. This result was also confirmed in female $\mathrm{PD}-\mathrm{L}^{-/-}$mice (Supplementary Figure 1A). LAG-3 blockade in WT mice promoted only a partial reduction of parasitemia compared to coblockade with anti-PD-L1 mAb. Further, treatment of PD- $1^{-/-}$mice with anti-LAG-3 mAb confirmed that LAG-3/PD-L1 co-blockade in WT mice resulted in a synergistic enhancement of parasite elimination (Supplementary Figure 1B). Therapeutic blockade of PD-1 in PD-L1 ${ }^{-/-}$mice, which neutralizes PD-1/PD-L2 interactions, resulted in delayed blood parasite clearance, consistent with a prior report (14) showing that blockade of the PD-1/PD-L2 axis prevents effective parasite control (Supplementary Figure 1C). Interestingly, blood parasitemia was comparable in anti-LAG-3/PD-1 versus antiLAG-3 treated PD-L1 ${ }^{-/}$mice, suggesting that inhibition of LAG-3 is dominant over that of PD-1/PD-L2. Collectively, these findings i) confirm the importance of PD-1-dependent and LAG-3 inhibitory pathways in resistance to malaria infection and ii) reveal that blockade of a specific inhibitory pathway, here LAG-3, can have distinct impacts depending on genetic or functional deficiencies in other related pathways, here PD-L1 or PD-L2.

\section{$B$ and CD4+ T Cell Responses in PD1-/-, PD-L1-/- and Heterozygous Littermates Are Comparable to That of Wild Type Mice}

Since $\mathrm{PD}^{-1-}, \mathrm{PD}_{-} \mathrm{L1}^{-1-}$ and WT mice exhibited similar resistance to $P y$ infection as WT mice, we next wondered whether adaptive cellular immune responses may still differ between these mice. As an initial step, we characterized the immune response in $P y$-infected WT mice over the $\sim 25$ day infection course. Since B cells play an essential role in protective immunity against malaria $(8,15)$, we carried out an in-depth kinetic analysis of this cellular compartment in the spleen of $P y$-infected mice at 7.5, 12.5, and 15.5 days post infection (Supplementary Figure 2). Using advanced flowcytometry gating strategies to define subsets of splenic B cells (16), we subdivided the $\mathrm{CD}_{19}{ }^{+} \mathrm{B}$ cells based on IgD and IgM cell-surface expression (Supplementary Figure 2A). By day 7.5, and peaking at day 12.5 of $P y$-infection, $\sim 40 \%$ of $\mathrm{CD}^{+} 9^{+} \mathrm{B}$ cells underwent isotype switching, becoming $\operatorname{IgM}^{\text {low }} \operatorname{IgD}^{\text {low }}$, while proportions of all other B cell subpopulations decreased. $\operatorname{IgM}^{\text {low }} \operatorname{IgD}^{\text {hi }}$ B cells modestly diminished over the infection course, and represented $\sim 50 \%$ of $\mathrm{CD} 19^{+} \mathrm{B}$ cells that include type I follicular B cells (FOL I) (Supplementary Figure 2B). We also noted reduction of 
IgM $^{\text {hi }} \operatorname{IgD}^{\text {low }} \mathrm{B}$ cells, which likely converted to marginal zone (MZ) B cells and B1 B cells. Proportions of all B cell transitional stages (T1, T2, T3) decreased during infection, yet marginal zone precursors (MZPs) and type II follicular B cells (FOL II) were largely maintained. The most noticeable changes occurred in the germinal centers (GC, $\mathrm{GL}^{+} \mathrm{CD}^{+} 5^{+}$) representing $\sim 15 \%-23 \%$ of splenic B cells between day 7.5 and 15.5 post infection (Supplementary Figure 2C). Plasmablast generation $\left(\mathrm{CD}_{138^{+}} \mathrm{PNA}^{+}\right.$) quickly increased following $P y$-infection, peaking by day 7.5 , and represented $\sim 7$ $10 \%$ of the splenic B cells. Production of effective GC and plasma B cell responses requires $\mathrm{CD} 4^{+} \mathrm{T}_{\mathrm{FH}}$ cell responses (17). As expected, a substantial proportion of $\mathrm{T}_{\mathrm{FH}}$ cells $\left(\mathrm{ICOS}^{+} \mathrm{Bcl}^{+}\right.$) formed by 7.5 days post infection $\left(\sim 30 \%\right.$ of $\mathrm{CD} 4^{+} \mathrm{T}$ cells) while only few follicular regulatory $\mathrm{T}$ cells $\left(\mathrm{T}_{\mathrm{FR}}\right.$, Foxp $\left.3^{+} \mathrm{Bcl}^{+}\right)$were generated by this time point, representing $\sim 7 \%$ of Foxp $3^{+} \mathrm{T}$ cells and $\sim 0.5-1 \%$ of all CD $4^{+} \mathrm{T}$ cells (Supplementary Figure 3A).

Using the knowledge gained from this comprehensive analysis of the robust $\mathrm{B}$ cell and associated $\mathrm{CD} 4^{+} \mathrm{T}_{\mathrm{FH}}$ cell responses induced after blood stage $P y$ infection, we next compared these responses at key time points (days 7.5 and 13.5) in $P y$-infected $\mathrm{PD}^{1^{--}}, \mathrm{PD}^{\mathrm{L}} 1^{-/-}$and WT mice (Figure 2). GC formation and plasmablast, $\mathrm{CD} 4^{+} \mathrm{T}_{\mathrm{FH}}$ and $\mathrm{T}_{\mathrm{FR}}$ cell differentiation at 7.5 and 13.5 days post infection were equivalent between all groups of mice (Figures 2A, B and Supplementary Figure 3B). We also assessed if $\mathrm{T}$ cells isolated from the various groups of $P y$-infected mice were functionally distinct compared to non-infected counterparts, by measuring the production of effector cytokines (IL-2, TNF, IFN $\gamma$ ). In splenocytes from naïve or $P y$-infected WT mice, the proportion of single and double cytokine-secreting $\mathrm{CD}^{+}$and $\mathrm{CD} 8^{+} \mathrm{T}$ cells after short ex vivo restimulation with $\mathrm{PMA} /$ ionomycin, was significantly reduced compared to that of uninfected controls (by $\sim 75 \%-90 \%$ ) (Supplementary Figure $3 \mathrm{C}$ ). In $\mathrm{PD}-1^{-/-}, \mathrm{PD}-\mathrm{L}^{-/-}$and heterozygous mice, we measured a comparable loss of cytokinesecreting capacity compared to that of naïve mice, yet comparable proportions were found in all groups (Figure 2C and Supplementary Figure 3D). Thus, altogether, the lack of observed differences in i) blood parasite growth and elimination, ii) $\mathrm{B}$ and $\mathrm{CD} 4^{+} \mathrm{T}_{\mathrm{FH}}$ cell responses and iii) production of effector cytokines across the distinct experimental groups, suggest a relatively modest contribution of the PD1/PD-L1 pathway in natural protection against blood stage malaria. These results are in contrast with prior published reports using PD-L1 Ab blockade in WT mice $(8,13)$.

\section{LAG-3 Neutralization in PD-L1-/- Mice Neither Promotes Greater CD4+ TFH, GC and Plasmablast Cellular Responses nor Higher Parasite-Specific Antibody Titers With Enhanced Protective Capacity}

Since the reported mechanism by which LAG-3/PD-L1 blockade in WT mice enhances parasite clearance is through greater GC B and $\mathrm{CD} 4^{+} \mathrm{T}_{\mathrm{FH}}$ cell responses and higher titers of parasite-specific Abs (8), we hypothesized that LAG-3 neutralization in PD-L1 ${ }^{-1-}$ mice may work through a similar mechanism. We monitored both $\mathrm{CD}^{+} \mathrm{T}_{\mathrm{FH}}$ and $\mathrm{B}$ cell GC and plasmablast responses in PD$\mathrm{L}^{-1-}$ and WT mice treated with anti-LAG-3 or anti-LAG-3/PDL1, respectively (Figure 3A). While as expected, blockade of
LAG-3 and PD-L1 in WT mice promoted significantly enhanced $\mathrm{T}_{\mathrm{FH}}$ and GC B cell responses, we did not find any differences in these cell populations in anti-LAG-3-treated PD-L1 ${ }^{-/-}$mice. Of note, spleen weight, and total or hematopoietic-derived $\left(\mathrm{CD} 45^{+}\right)$ cell counts per spleen were comparable in WT and PD-L1 ${ }^{-/-}$mice undergoing the various treatments, likely ruling out that the lack of differences in cell subset proportions in the distinct experimental groups is due to differences in absolute cell numbers (Supplementary Figure 4).

We next conducted experiments to assess if despite the lack of obvious differences in $\mathrm{B}$ and $\mathrm{CD} 4^{+} \mathrm{T}_{\mathrm{FH}}$ cell responses in $\mathrm{PD}-\mathrm{L1}^{-/}$ mice, parasite-specific Abs produced in anti-LAG-3-treated mice may still confer better protection and exhibit higher serum titers compared to isotype-treated counterparts (Figure $3 \mathbf{B}$ ). We transferred sera $(150 \mu \mathrm{l} /$ mouse, one time $)$ isolated from antiLAG-3 or isotype Ab-treated PD-L1 ${ }^{-/-}$mice 18, 32, or 72 days post $P y$-infection, into $\mathrm{WT} B 6$ recipient mice that were subsequently infected with $P y$. Data reveal a delayed onset and peak blood parasitemia, and lower weight loss in mice treated with day 72 sera, but no beneficial trends were observed in day 18 or 32 sera transfers. This result was extended in sera isolated from day 32 $P y$-infected WT mice treated with anti-LAG-3/PD-L1 or isotype control Abs, suggesting that, at least under these experimental conditions, transfer of parasite-specific Abs from $P y$-infected mice failed to confer significantly distinct levels of protection to recipient mice (Supplementary Figure 5A). Yet, immune sera from day 72-infected WT mice did confer increased protection and prevented weight loss compared to pre-immune sera, validating our serum transfer experiments and read-outs. Along these lines, only sera from day 72 anti-LAG-3, but not isotype-treated infected $\mathrm{PD}-\mathrm{L1}^{-/-}$mice, delayed parasitemia in recipient mice that were subsequently infected, suggesting that $\mathrm{PD}-\mathrm{L1}^{-/-}$mice are unable to develop long-term parasite-specific protective Abs (Figure 3B). Comparative day 32 sera transfers between isotype Ab-treated WT and $\mathrm{PD}-\mathrm{L1}^{-/-}$mice showed no differences in parasitemia in recipient mice, yet slightly better $P y$ clearance and lower weight loss for day 72 sera from WT mice was observed compared to that of $\mathrm{PD}-\mathrm{L}^{-1-}$ mice (Supplementary Figure 5B). This result was consistent with the idea that $\mathrm{PD}-\mathrm{Ll}^{-/-}$mice do not develop effective parasite-specific protective Abs.

To provide additional evidence to these findings, we also measured parasite-specific Ab titers using the recombinant merozoite surface antigen $M S P 1_{19}$, a major blood stage parasite antigen (Ag) (Figure 3B and Supplementary Figure 5A). Consistent with the serum transfer experiments, titers of parasitespecific Abs specific for $\mathrm{MSP}_{19}$ in the sera of anti-LAG-3 versus isotype $\mathrm{Ab}$-treated $\mathrm{PD}-\mathrm{L1}^{-/-}$mice (day 18, 32) did not reveal significant differences. Slightly higher Ab titers were nevertheless measured in day 72 sera from anti-LAG-3-treated $\mathrm{PD}-\mathrm{L1}^{-/-}$mice, in line with the observed delayed parasitemia results (Figure 3B). Likewise, slightly higher parasite-specific $\mathrm{Ab}$ titers were quantified in day 72 sera from anti-LAG-3/PD-L1-treated WT mice (Supplementary Figure 5A).

These results suggest that the mechanism, by which LAG-3 blockade in PD-L1 ${ }^{-/-}$mice and LAG-3/PD-L1 co-blockade in WT mice enable the rapid control of blood parasitemia, is 


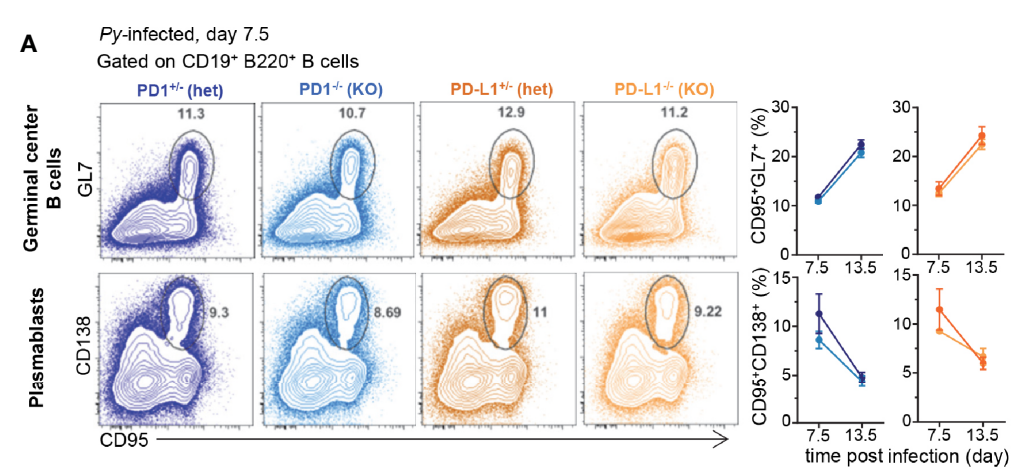

B Py-infected, day 7.5
$\quad$ Gated on CD4 $4^{+}$Foxp3neg $T$ cells

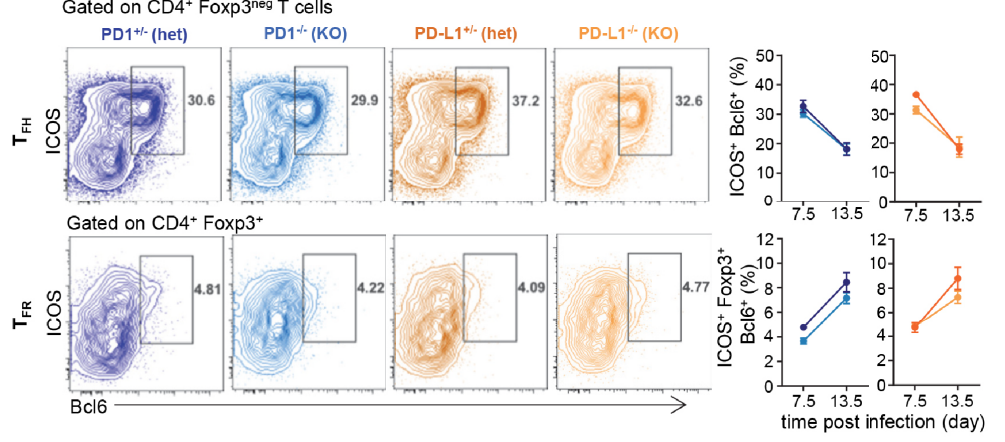

C Py-infected, day 13.5

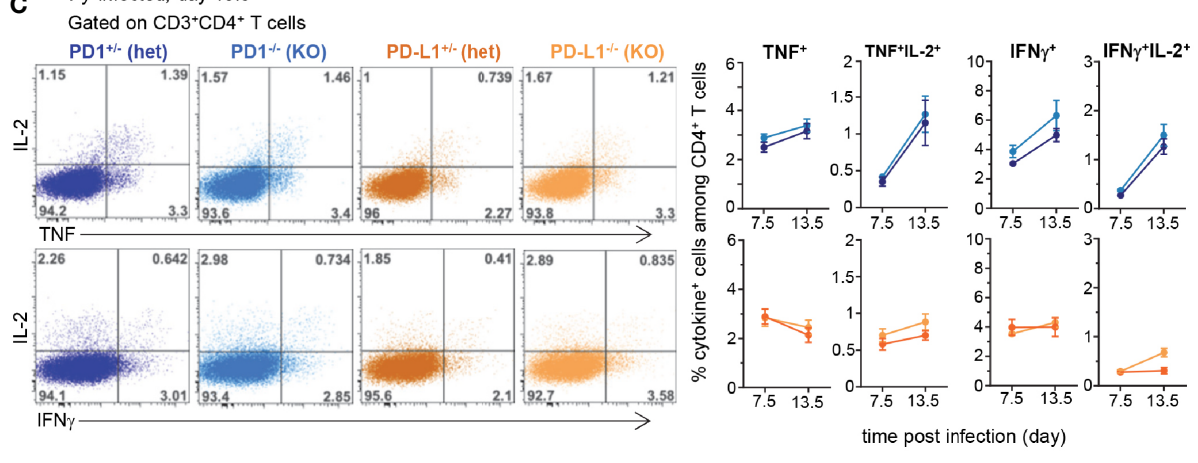

FIGURE 2 | B and CD4 ${ }^{+}$T cell responses are comparable in Plasmodium yoelii-infected PD1 ${ }^{-/}$, PD-L $1^{-/-}$, and heterozygous counterparts littermates. Littermates of indicated genotypes were inoculated with $2 \times 10^{5}$ Py $17 X N L 1.1$ (iRBC) i.v. (A) Spleens from Py-infected mice were harvested 7.5 and 13.5 days post infection and stained for CD19, B220, GL7, CD138, CD95 to monitor B cell responses and (B) spleen cells were stained for CD4, CD3, Foxp3, Bcl6, ICOS to monitor CD4 ${ }^{+} T_{F H}$ and $T_{F R}$ cellular

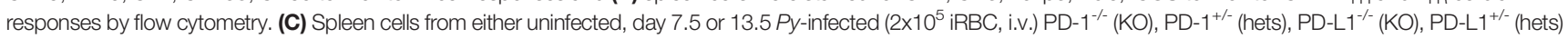
mice were incubated with PMAVionomycin for $4 \mathrm{~h}$ and then stained for cell-surface CD3, CD4 and CD8 and intracellular cytokines IL-2, IFN $\gamma$, and TNF. Frequencies of cytokine-producing cells among indicated T cell subset are shown. In all experiments, representative FACS dot plots of two independent replicate experiments are presented $(n=3-12)$. Graphs show average results from experiments with SEM. Student t-test was conducted between groups and $p$-values are indicated when applicable.

unlikely to involve the production of higher titers of parasitespecific Abs. Also consistent with prior studies, our data show that peak production of such protective Abs most likely occurs within 2-3 months after infection, but not at early stages (18).

\section{CD4+ T Cells From Anti-LAG-3-Treated PD-L1-/- Mice Express More Effector Cytokines Compared to Untreated Counterparts}

Our results so far led us to hypothesize that blockade/disruption of the LAG-3 and PD-1/PD-L1 pathways enhances rapid parasite clearance via $\mathrm{CD} 4^{+} \mathrm{T}$ cells, independent from humoral response. Since therapeutic blockade of these pathways was also shown to restore malaria-induced $\mathrm{T}$ cell dysfunction $(8,9)$, we next tested if $\mathrm{T}$ cells isolated from LAG-3-treated PD-L1 ${ }^{-/-}$mice were more responsive to broad PMA/ionomycin stimulation than control groups at day 17, when rapid parasite elimination is observed (Figure 1). We report significant differences by a factor of 2-3 fold, in the relative proportion and numbers of single (IL- $\left.2^{+}\right)$and double (IL-2/TNF ${ }^{+}, \mathrm{IL}_{-2} / \mathrm{IFN}^{+}, \mathrm{IFN} / \mathrm{TNF}^{+}$) cytokine-secreting $\mathrm{CD}^{+}$, but not $\mathrm{CD}^{+}$, $\mathrm{T}$ cells in the anti-LAG-3-treated group compared to the control group, consistent with our hypothesis 


\section{A}

Py 17 XNL1.1, day 17

Gated on $\mathrm{CD}^{+} \mathrm{T}$ cells:

Uninfected
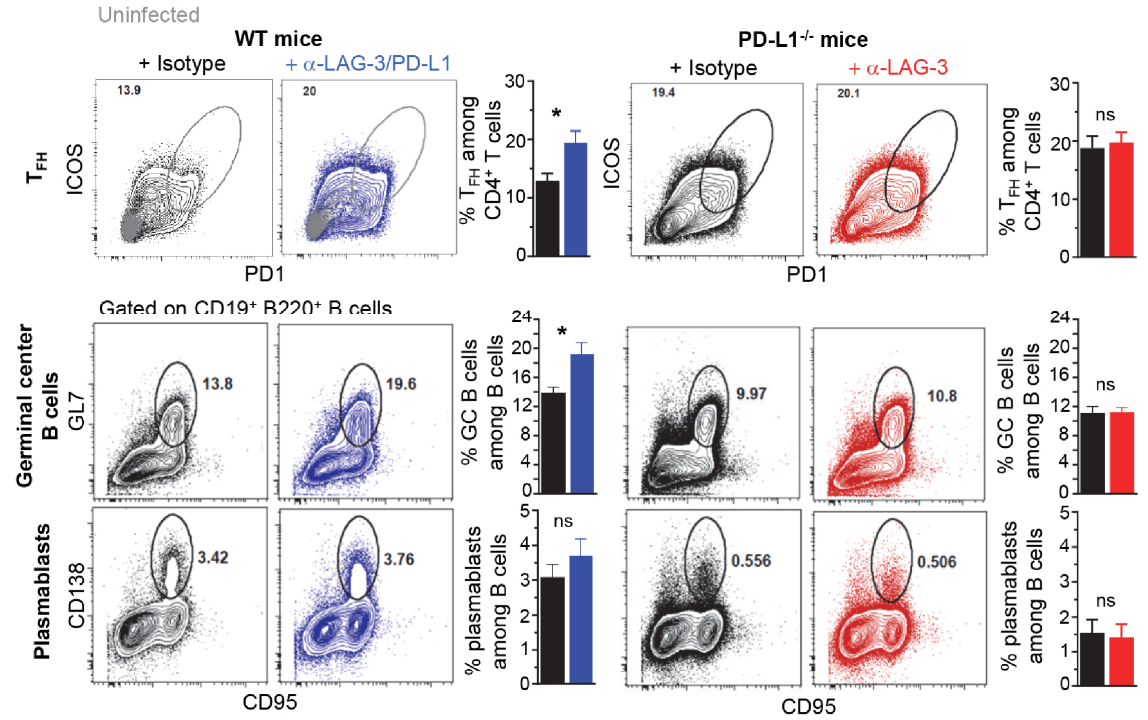

B

Sera transferred from PD-L1- mice to WT mice from:

Pre-immune or Py-infected: Isotype, $\alpha$-LAG-3
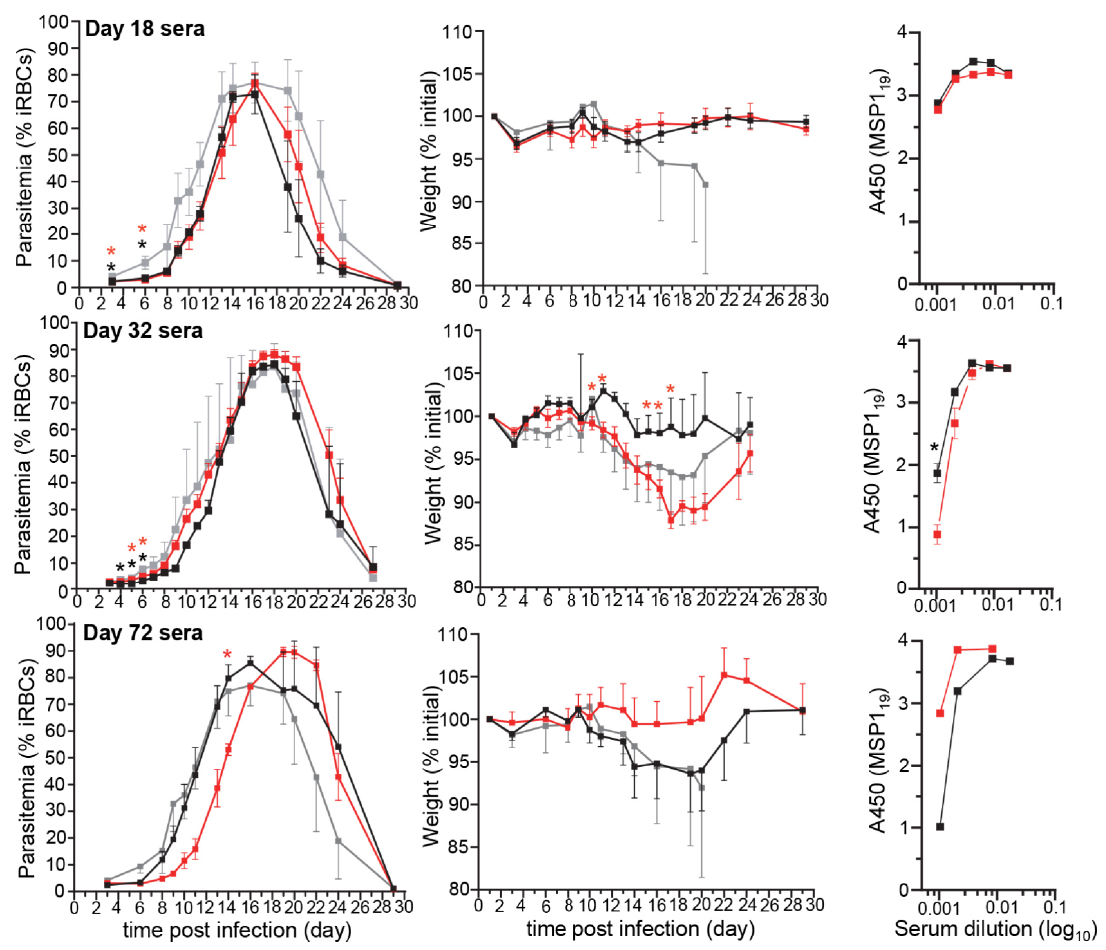

FIGURE 3 | Lymphocyte Activation Gene 3 (LAG-3)/PD-L1 therapeutic blockade enhances $T_{\text {FH }}$ and germinal center (GC) responses while LAG-3 blockade in PDL $1^{-1-}$ mice does not. (A) Wild-type (WT) B6 or PD-L1/- mice were inoculated with $2 \times 10^{5}$ Py $17 X N L 1.1$ iRBC i.v. and 9, 12, 15, and 18 days post infection, indicated mice either received $200 \mathrm{\mu g}$ of either anti-LAG-3/PD-L1, anti-LAG-3 or isotype Ab i.v. Spleens were harvested 17 days post infection and stained for CD4, CD3, ICOS, PD-1 to monitor CD4 ${ }^{+} T_{F H}$ cell response (ICOS ${ }^{+}$PD- $1^{\text {hi }}$ corresponds to ICOS ${ }^{+} B c l 6^{\text {hi }}$ cells) (top panel) and for CD19, B220, GL7, CD138, CD95 to monitor B cell responses (lower panels). Representative FACS dot plots of one to two independent replicate experiments are presented $(n=4-10)$, with an overlay of representative uninfected mouse in the WT top panel. Graphs average each experiment shown with SEM. Student t-test was conducted between groups and $p$-values are indicated when applicable $\left({ }^{*} \mathrm{p}<0.05\right)$. (B) $150 \mu$ l of sera harvested from mice 18, 32, or 72 days post Py-infection was transferred to naïve WT mice (35 mice/group) that were subsequently infected with $2 \times 10^{5}$ Py $17 X N L 1.1$ iRBC i.v. Blood parasitemia and weight was monitored over 28 days. Titers of Py MSP1 ${ }_{19}^{-}$ specific $\lg G$ antibodies in indicated sera was measured by ELISA and reported as background subtracted $A_{450}$ values. $p$-values are indicated when possible compared to pre-immune treatment or to isotype treatment by student t-test. Asterisk color indicate respective treatment group ( $\left.{ }^{*} p<0.05\right)$. 
(Figures 4A, B). While a higher proportion of anti-LAG-3treated $\mathrm{CD}^{+} \mathrm{T}$ cells accumulated effector and proliferative cytokines, the distribution of the various phenotypic and functional subsets of $\mathrm{CD}^{+}$and $\mathrm{CD}^{+} \mathrm{T}$ cells $\left(\mathrm{T}_{\mathrm{FH}}, \mathrm{T}_{\text {reg }}, \mathrm{T}_{\mathrm{FR}}\right.$, Ag-experienced) remained similar between all experimental groups and conditions (Figures 4C and 3A). High dimensional flow-cytometry analysis of the $\mathrm{CD}^{+} \mathrm{T}$ cells at later stages (day 36) with 25 colors (Supplementary Figure 6A), also failed to further reveal any differences in subsets of $\mathrm{CD} 4{ }^{+} \mathrm{T}$ cells (T-bet, $\mathrm{T}_{\mathrm{FH}}$ ), activation/memory status (CD62L, CD44, CD11a) and proliferation (Ki67) between anti-LAG-3 and control isotype $\mathrm{Ab}$-treated $\mathrm{PD}-\mathrm{L1}^{-/}$mice (Figure 4D and Supplementary Figure 6B). In summary, LAG-3 blockade contributes to rescuing malaria-induced $\mathrm{CD} 4^{+} \mathrm{T}$ cell dysfunction in $\mathrm{PD}-\mathrm{L}^{-/}{ }^{-}$mice, but does not appear to modulate their ability to differentiate into various functional and memory subsets of $\mathrm{T}$ cells.

\section{Antigen-Experienced $\mathrm{T}_{\text {bet }}^{+} \mathrm{CD}^{+}$and $\mathrm{T}_{\text {bet }}^{+}$, $\mathrm{T}_{\mathrm{FH}}$ and $\mathrm{T}_{\mathrm{FR}} \mathrm{CD4}^{+} \mathrm{T}$ Cells Are the Major LAG-3-Expressing Cell Subsets}

To gain further insight into how LAG-3 blockade contributed to reduced blood parasitemia, we next investigated which cells express the LAG-3 receptor during $P y$ infection (Figure 5). LAG-3expressing spleen cells represented $\sim 8.5 \%$ of live cells by day 7.5 post- $P y$ infection and largely consisted of T cells $(>80 \%)$ that make up $\sim 26 \%$ of splenic cells, distributed among $\mathrm{CD} 4^{+}$and $\mathrm{CD} 8^{+} \mathrm{T}$ cells (Figures 5A, B). Among LAG- $3^{+} \mathrm{CD} 4^{+} \mathrm{T}$ cells, a majority were activated $\mathrm{ICOS}^{+}$conventional T cells $(\sim 48 \%), \mathrm{T}_{\mathrm{FH}}$ cells $(\sim 33 \%)$ and $\mathrm{T}_{\mathrm{FR}}$ cells $(\sim 32 \%)$. Some Foxp $3^{+} \mathrm{T}_{\text {reg }}$ cells also expressed LAG-3 but only represented a small proportion of all $\mathrm{CD} 4^{+} \mathrm{T}$ cells $(<6 \%)$. Using high dimensional flow cytometry we assessed cell-surface lineage, activation and intracellular functional markers, as well as lineage specifying transcription factors. We found that activated and proliferating $\left(\mathrm{CD} 62 \mathrm{~L}^{\text {lo }} \mathrm{CD} 44^{\mathrm{hi}} \mathrm{Ki} 67^{+}\right) \mathrm{CD}^{+} \mathrm{T}$ cells distributed into $\mathrm{T}_{\text {bet }}^{+}$, Eomes ${ }^{+}$and $\mathrm{T}_{\text {bet }}^{+} /$Eomes $^{+}$effector cells (Figure 5C). $\mathrm{T}_{\text {bet }}^{+}$cells expressed high levels of the cytolytic marker granzyme B and cell-surface marker CX3CR1, which are features of terminally differentiated effector cells (19). Interestingly, activated and proliferating $\mathrm{CD}^{+} \mathrm{T}$ cells mostly included $\mathrm{T}_{\text {bet }}^{+}$and $\mathrm{T}_{\mathrm{FH}}$ cells, both of which expressed high levels of the cell-surface marker ICOS (Figure 5D). In contrast, ICOS ${ }^{\text {neg }} \mathrm{CD}^{+} \mathrm{T}$ cells were not activated (CD62L ${ }^{\text {hi }} \mathrm{CD} 44^{\text {lo }} \mathrm{Ki}^{\text {neg }}$ ) (Supplementary Figure 6C). Interestingly, using CD49d and CD11a cell-surface markers as a proxy for activated parasite-specific $\mathrm{T}$ cells, we found a substantial proportion of LAG- $3^{+} \mathrm{T}$ cells expressed both markers ( $\sim 84 \%$ and $\sim 38 \%$ respectively, for $\mathrm{CD}^{+}$and $\mathrm{CD}^{+} \mathrm{T}$ cells) and $>90 \%$ also upregulated the adhesin CD11a (Figure 5E). A large proportion of $\mathrm{CD} 4 \mathrm{~d}^{+} / \mathrm{CD} 1 \mathrm{a}^{+} \mathrm{CD}^{+}$and $\mathrm{CD} 4^{+} \mathrm{T}$ cells were activated and proliferated $\left(\mathrm{CD} 62 \mathrm{~L}^{\mathrm{lo}} \mathrm{CD} 44^{\mathrm{hi}} \mathrm{Ki} 67^{+}\right)$, and expressed $\mathrm{T}_{\text {bet }}$, Eomes and were $\mathrm{T}_{\mathrm{FH}}$ (for $\mathrm{CD}^{+} \mathrm{T}$ cells) (Figure 5F). Lastly, consistent with our prior results (Figure 2), analysis of LAG- $3^{+} \mathrm{T}$ cells in $P y$ infected (day 7.5) PD- $\mathrm{L1}^{-/-}$and $\mathrm{PD}-1^{-/-}$mice failed to reveal any differences of subset distribution between them, and compared to WT counterparts (Figures 5G, B). Thus, these data support a model in which the largest proportion of LAG- $3^{+}$cells are $\mathrm{T}$ cells that are likely parasite-specific, and include effector $\mathrm{T}_{\text {bet }}^{+} \mathrm{CD} 8^{+} \mathrm{T}$ cells and $\mathrm{T}_{\text {bet }}^{+}, \mathrm{T}_{\mathrm{FH}}$ and $\mathrm{T}_{\mathrm{FR}} \mathrm{CD} 4^{+} \mathrm{T}$ cells.
The major ligand for LAG-3 is MHC-II. In an effort to provide additional insights into which cells may be regulating LAG- $3^{+} \mathrm{CD} 4{ }^{+}$ $\mathrm{T}$ cells, we analyzed MHC-II ${ }^{+}$cell subsets in $P y$-infected mice (Supplementary Figure 6D). While the vast majority of $\mathrm{MHC}-\mathrm{II}^{+}$ cells were B cells (50\%), we observed that DCs (1.7\%), Ly6C ${ }^{+}$ monocytes (2\%) and neutrophils (2.7\%) also expressed MHC-II. Expression levels were highest on DCs, followed by B cells, in both uninfected and infected mice, and $P y$-infection induced upregulation on most of these cell subsets. Comparison of MHC-II expression on these cells in $P y$-infected PD-L1 ${ }^{-/}, \mathrm{PD}-1^{-/-}$and WT mice highlighted slight but significantly increased frequencies in $\mathrm{MHC}-\mathrm{II}^{+} \mathrm{DCs}$ and monocytes in $\mathrm{PD}-\mathrm{L1}^{-/}$and $\mathrm{PD}-1^{-/-}$compared to WT mice (Supplementary Figure 6E). However, the relative distribution of MHC- $\mathrm{II}^{+}$cells was the same in all groups. Thus altogether, these results suggest that $\mathrm{B}$ cells and DCs may represent the most likely regulators of activated LAG $-3^{+} \mathrm{CD} 4^{+} \mathrm{T}$ cells.

\section{Anti-LAG-3-Mediated Parasite Elimination Is Independent From CD8+ T Cells}

Since the major $\mathrm{LAG}_{-} 3^{+}$cell types are $\mathrm{CD} 8^{+}$and $\mathrm{CD} 4^{+} \mathrm{T}$ lymphocytes, we next tested if selective depletion of either $\mathrm{T}$ cell subset would abrogate the LAG-3-mediated protective effect (Figure 6). PD-L1 ${ }^{-/-}$mice were either injected with anti-CD8 $\beta$ or anti-CD4 depleting $\mathrm{mAb}$ or $\mathrm{PBS}$ prior to infection with $P y$, and 9 , 12 , and 15 days post-infection, mice received anti-LAG-3 or control isotype Abs. We monitored weight and parasitemia every other day until the undepleted isotype Ab-treated control groups were negative for blood parasitemia. LAG-3 blockade in $\mathrm{CD}^{+} \mathrm{T}$ celldepleted PD-L1 ${ }^{-/-}$mice enhanced the control and clearance of blood parasitemia similarly to that of undepleted control groups, indicating that anti-LAG-3 blockade does not act on $\mathrm{CD}^{+} \mathrm{T}$ cells. In contrast, $\mathrm{CD}^{+} \mathrm{T}$ cell-depleted mice failed to control parasite growth and developed chronic parasitemia, losing $>10 \%$ of initial body weight 20 days post-infection whether treated with anti-LAG-3 or control isotype Abs, and consistent with their requirement for $P y$ parasite clearance (8). Taken together with the finding that LAG-3 is mostly expressed on T cells (Figure 5), these results suggest that the anti-LAG-3-mediated therapeutic effect on blood parasite elimination is likely to occur by blocking LAG-3 on parasite-specific $\mathrm{T}_{\text {bet }}^{+}$and/or $\mathrm{T}_{\mathrm{FH}} \mathrm{CD}^{+} \mathrm{T}$ cells, but not on $\mathrm{CD}^{+}$ T cells.

\section{DISCUSSION}

In this work, we investigated the mechanisms by which blockade of the inhibitory receptors LAG-3 and PD-L1 promote more effective control and clearance of non-lethal blood stage murine $P$. yoelii malaria. We reveal that LAG-3 neutralization in mice that are genetically deficient for PD-1/PD-L1 did not promote stronger $\mathrm{CD}^{+} \mathrm{T}_{\mathrm{FH}}$ and $\mathrm{GC} \mathrm{B}$ cell responses as it was reported in anti-PD-L1/ LAG-3 treated WT mice (8). Consistent with this result, convalescent sera (day 32 ) transfers from anti-LAG-3 treated PD$\mathrm{L1}^{-/-}$mice and anti-PD-L1/LAG-3 treated WT compared to control isotype $\mathrm{Ab}$ treated mice failed to confer distinct levels of protection against $P y$ infection in naïve recipient mice. Additionally, sera titers of parasite $\left(\mathrm{MSP}_{19}\right)$-specific Abs were comparable in all 


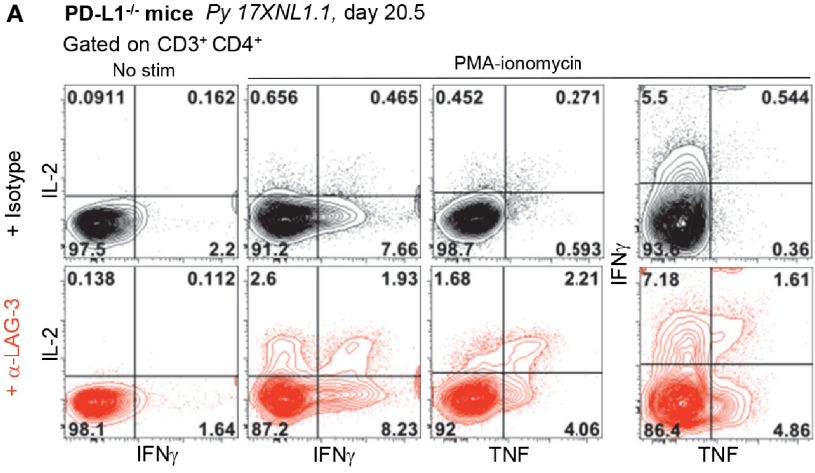

B

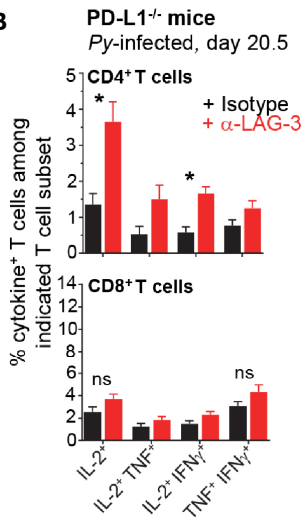

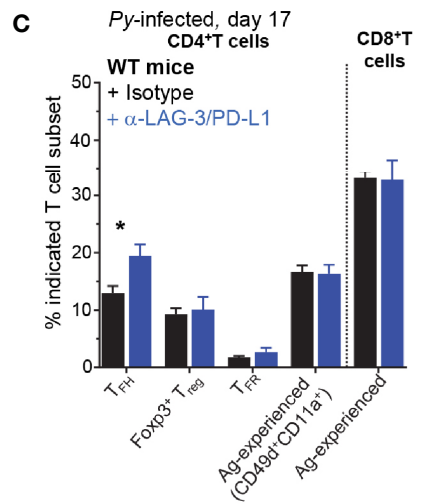
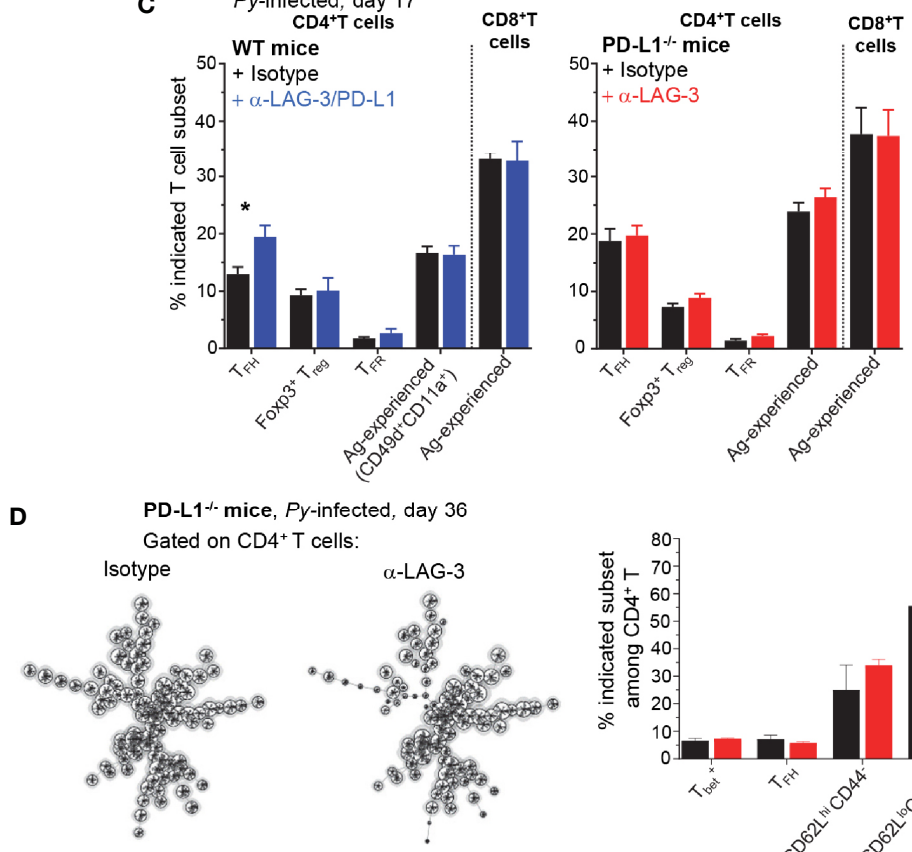

-L1\% mice, Py-infected, day 36 Gated on $\mathrm{CD} 4^{+} \mathrm{T}$ cells:
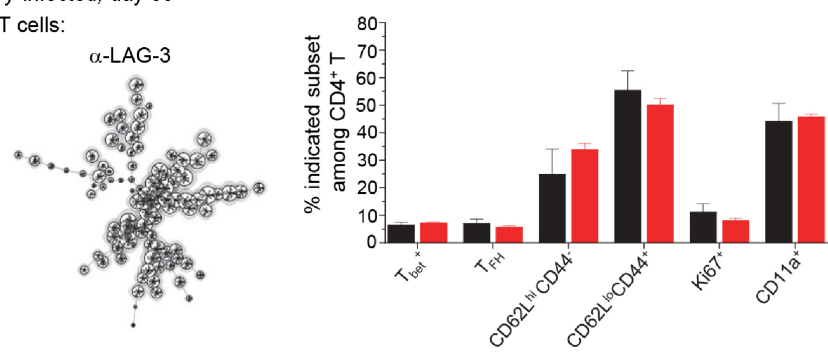

FIGURE 4 | Lymphocyte Activation Gene 3 (LAG-3) blockade in PD-L1 ${ }^{-1-}$ mice partially restores CD4 ${ }^{+} T$ cell dysfunction. Spleen cells from day 20.5 Py-infected PD-L1 ${ }^{-1-}$ or WT mice, treated with either anti-LAG-3/PD-L1, anti-LAG-3 or isotype Ab i.v. (as indicated, on days 9, 12, 15) were stained for cell-surface CD3, CD4 and CD8, Foxp3, Bcl6, ICOS and intracellular cytokines IL-2, IFN $\gamma$, and TNF after incubation with PMA/ionomycin for $4 \mathrm{~h}$ (T cell mix). (A) Representative FACS dot plots of two independent experiments are shown with the frequencies of cytokine-producing cells among $C D 4^{+} T$ cells $(n=3-5)$. (B) Graphs of the average frequencies of cytokine-producing cells among CD4 ${ }^{+} \mathrm{T}$ cells (shown in (A)) and CD8 ${ }^{+} \mathrm{T}$ cells with SEM. P-values are indicated when applicable. (C) Distribution of known splenic $T$ cell subsets as indicated on day 17 post infection, $T_{F H}$ data are from the same experiment shown in Figure 7. Graphs average one to two independent experiments ( $n=4-5$ ) shown with SEM. (D) Spleen cells from day 36 PD-L1 ${ }^{-/-}$Py-infected mice treated with either anti-LAG-3 or isotype Ab i.v. (on days $9,12,15)$ were stained for lineage markers (CD8, CD4, CD3, Bcl6, Tbet) and functional markers (CD62L, CD44, CD11a) with a 24 color panel depicted in S3A Fig. FlowSOM analysis (left) on pooled CD4 $4^{+}$cells $(n=5)$ and summary bar graphs from each treatment group are shown (right). Distribution of known splenic $T$ cell subsets as indicated on day 36 post infection. Student t-test was conducted between groups and $p$-values are indicated when applicable ( $\left.{ }^{\star} p<0.05\right)$.

immunized groups of mice. We further found that LAG-3, at the time of $\mathrm{Ab}$ blockade, is mostly expressed by $\mathrm{T}$ cells, with a large majority consisting of activated, proliferating Ag-experienced $\left(\mathrm{CD} 4 \mathrm{~d}^{+} \mathrm{CD} 11 \mathrm{a}^{+}\right) \mathrm{T}$ cells that include $\mathrm{T}_{\text {bet }}^{+} \mathrm{CD}^{+}$and $\mathrm{ICOS}^{+}, \mathrm{T}_{\mathrm{FH}}$ and $\mathrm{T}_{\mathrm{FR}} \mathrm{CD} 4^{+} \mathrm{T}$ cells. We show that while both subsets of $\mathrm{T}$ cells express LAG-3, the protective effect of LAG-3-blockade does not require $\mathrm{CD}^{+} \mathrm{T}$ cells and thus is most likely mediated through $\mathrm{CD}^{+} \mathrm{T}$ cells. We also report that LAG-3 blockade enhances $\mathrm{CD} 4^{+} \mathrm{T}$ cell effector functions in infected mice. Thus, we propose a model in which inhibition of LAG-3 on parasite-specific $\mathrm{CD} 4^{+}$ $\mathrm{T}$ cells unleashes their ability to produce effector cytokines, altogether contributing to achieve superior levels of protection in malaria-infected hosts, independent from parasite-specific humoral responses.

Our finding that mice with genetic deficiency in the PD-1/PDL1 pathway are as susceptible to $P y$ malaria infection as their WT counterparts highlights some unexpected discrepancies with prior work showing that therapeutic mAb blockade of PD-L1 in WT mice 
A Gated on live cells
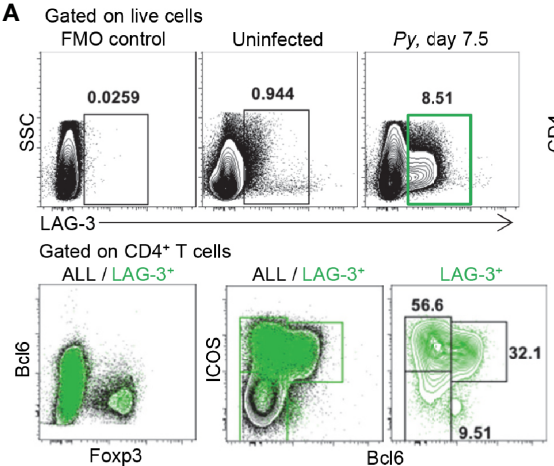

C
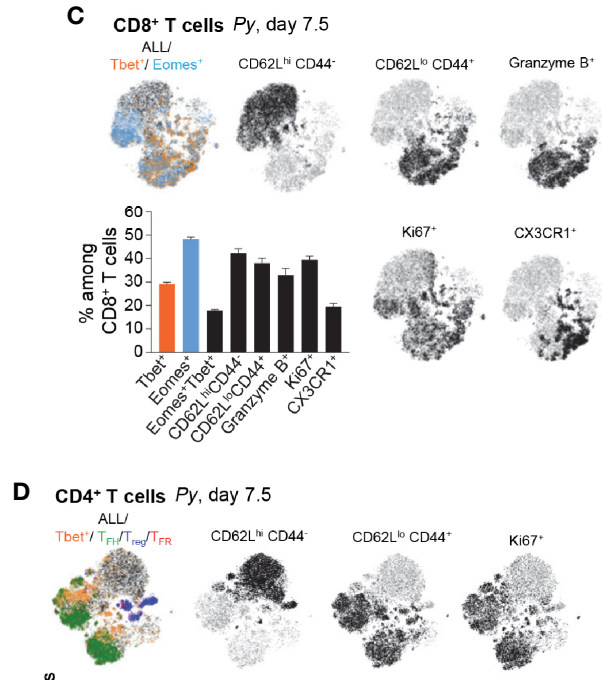
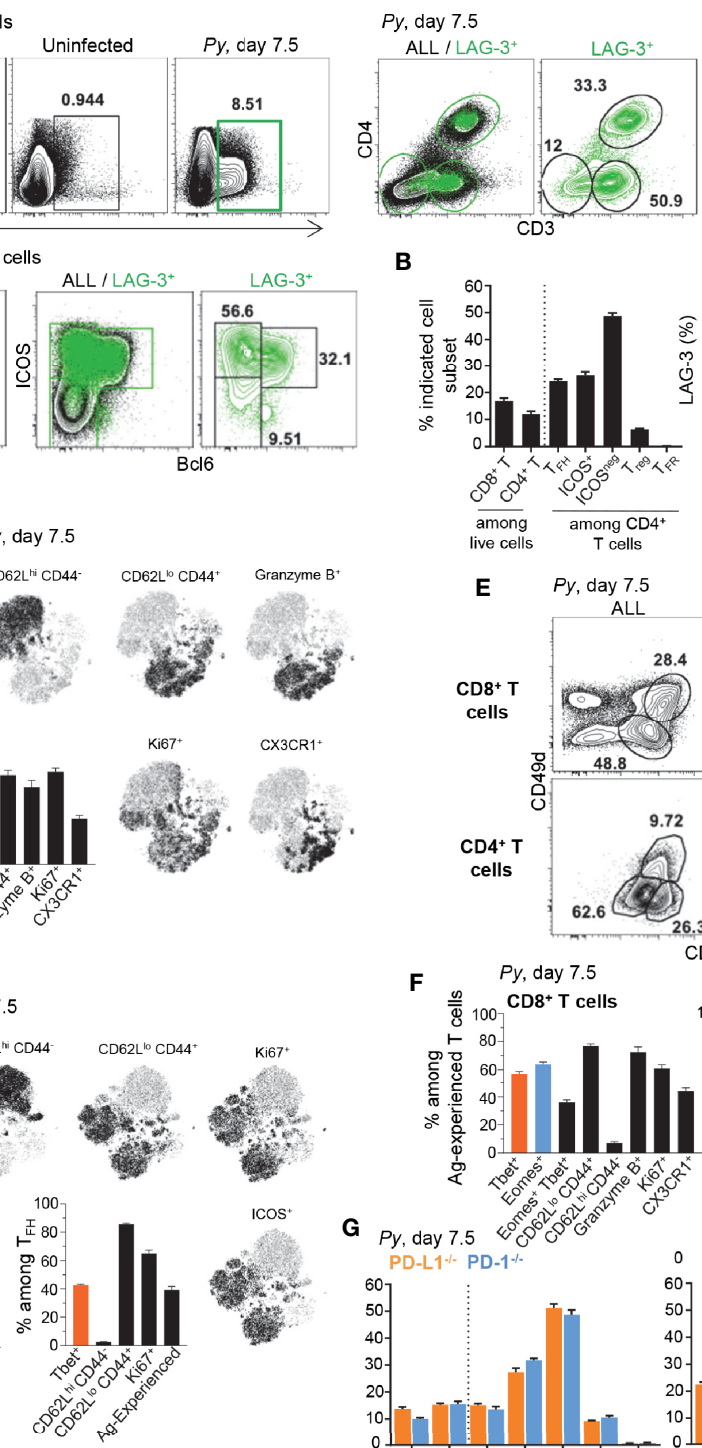

B

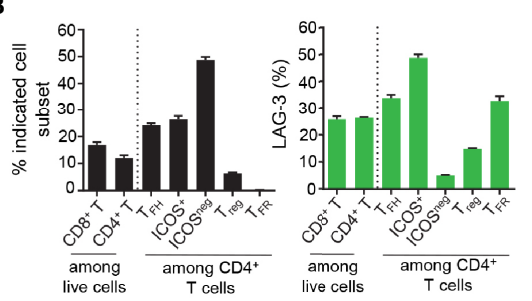

$$
\text { E Py, day } 7.5
$$

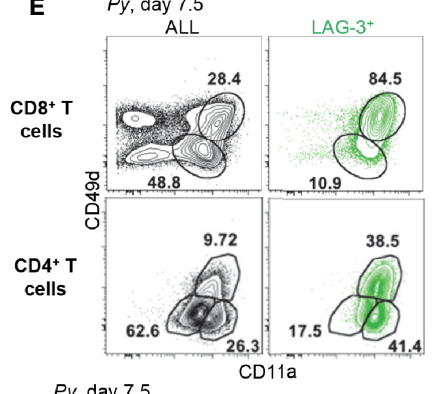

F
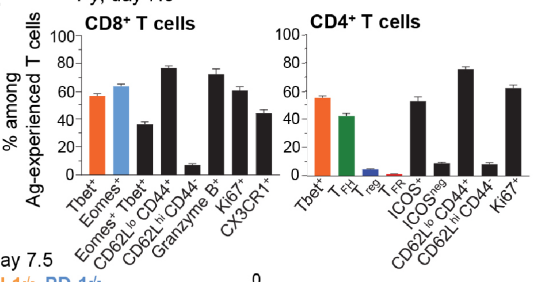

G Py, day $7.5<$
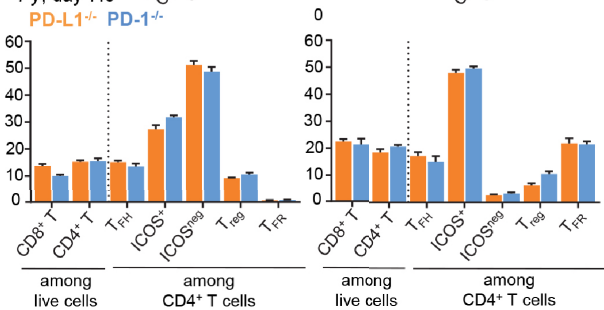

FIGURE 5 | Lymphocyte Activation Gene 3 (LAG-3) is expressed on activated CD4 ${ }^{+}$and CD8 ${ }^{+}$T cells during Py infection. Spleen cells from day 7.5 Py-infected mice were stained for lineage markers (CD8, CD4, CD3, Foxp3, Bcl6) and activation/inhibitory markers (LAG-3, CD11a, CD49d), or with a 26 color panel in S3A Figure (C, D, F). (A, B) FACS dot plots of the phenotype and (B) proportion of LAG-3-expressing cells among the indicated T cell subsets in WT mice. (C, D) t-SNE overlay representation of indicated $\mathrm{CD}^{+} \mathbf{( C )}$ and $\mathrm{CD}^{+}$(D) T cell subsets from a pool of five infected WT mice with bar graphs summarizing the proportions of indicated subsets with SEM. (E) Proportion of Ag-experienced (CD11 $\left.{ }^{+} \mathrm{CD} 49 \mathrm{~d}^{+}\right) \mathrm{CD}^{+}$and CD4 ${ }^{+} \mathrm{T}$ cells on all or LAG-3 cells. (F) Proportions of indicated subsets among Ag-experienced $\mathrm{CD}^{+}$and $\mathrm{CD} 4^{+} \mathrm{T}$ cells from the pool of five infected WT mice with SEM. (G) proportion of LAG-3-expressing cells among the indicated T cell subsets in PD-L1 $1^{-/-}$or PD-1 $1^{-1-}$ mice. Overall, representative FACS dot plots of two independent replicate experiments are presented for one of three to five mice. Graphs show average results from experiments with SEM. P-values are indicated when applicable.

promotes enhanced control and clearance of blood parasitemia (8, 13). The fact that i) the kinetics of infection was comparable in $P y$ infected PD- $1^{-/}, \mathrm{PD}-\mathrm{L1}^{-/}$, heterozygous and WT littermate mice, and ii) we did not find any differences in either $\mathrm{T}, \mathrm{B}$ cell or $\mathrm{Ab}$ responses despite extensive analyses, suggests that genetic deficiency in PD-1 and PD-L1 may favor the utilization of distinct mechanisms of resistance against this infection through otherwise redundant pathways. The indistinguishable kinetics of parasitemia in $\mathrm{PD}-\mathrm{1}^{-/-}$and $\mathrm{PD}-\mathrm{L1}^{-/-}$mice together with the LAG-3 blockade experiment support such an interpretation, since LAG-3 neutralization in $\mathrm{PD}-\mathrm{L}^{-/-}$mice promotes remarkable growth control and clearance of blood parasites, which in WT mice is only achieved upon co-blockade with PD-L1. A similar observation has been reported in a model of ovarian cancer in which therapeutic 


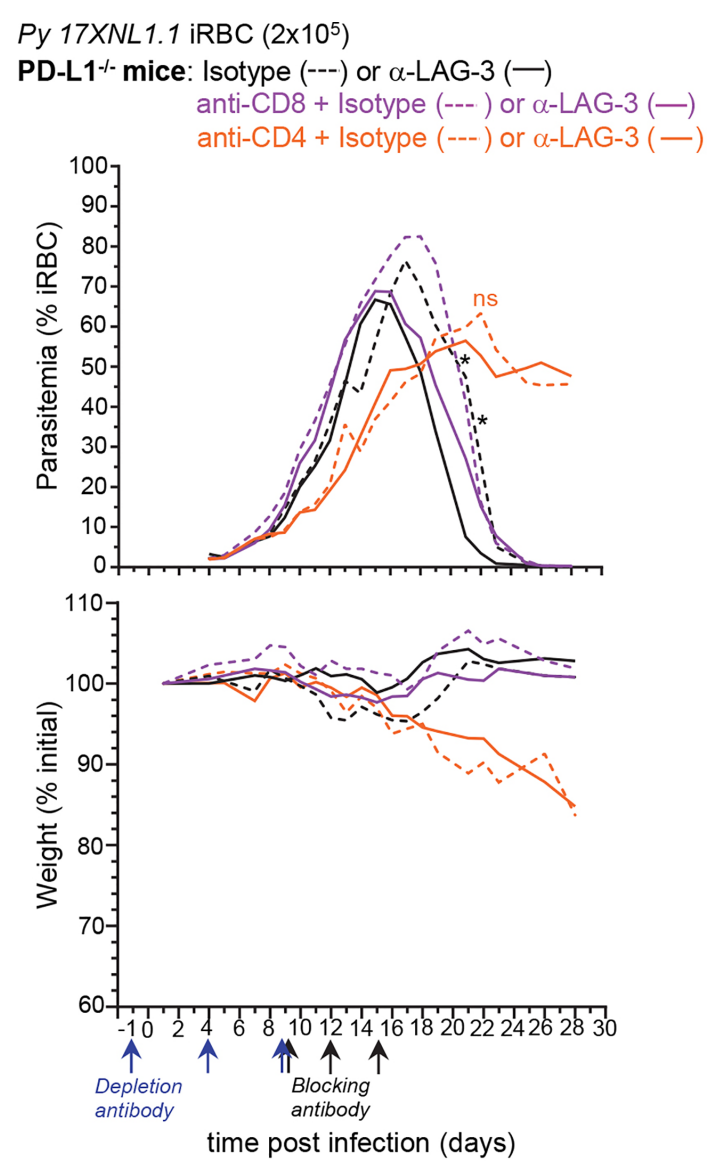

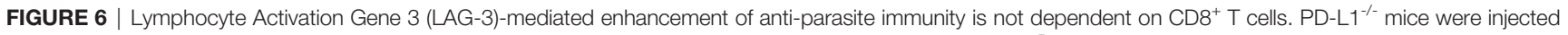
i.p. with PBS or $150 \mu \mathrm{g}$ of either anti-CD4 or anti-CD8 $\beta$ depleting mAbs as depicted and inoculated with $2 \times 10^{5}$ Py $17 X N L 1.1$ iRBC i.v. Mice also received either 300 $\mu \mathrm{g}$ anti-LAG-3 or isotype Ab i.v. on day 9, 12, and 15 post $P y$ infection. Results show blood parasitemia measured by YOYO-1 staining of RBC, and change in initial weight (lower panel) over time starting on day 4 post Py infection. Anti-CD8 $\beta+$ isotype $(n=3)$, anti-CD4 + isotype ( $n=7)$, Anti-CD8 $\beta+$ anti- $L A G 3$ ( $n=5)$, anti-CD4 + anti-LAG3 $(n=8)$, isotype $(n=4)$, anti-LAG3 $(n=5)$. Graphs are representative of two independent experiments $(n=3-4)$ shown with SEM. Student $t$-test was conducted between each treatment compared to isotype (asterisk color indicate respective group), $p$-values are indicated when applicable ( $\left.{ }^{*} p<0.05\right)$.

co-blockade of PD-1/LAG-3/CTLA-4 in WT mice leads to two times fewer tumor free mice compared to anti-LAG-3/CTLA-4 treatment in $\mathrm{PD}-1^{-/-}$mice (20). These results further illustrate a more generally accepted dogma that mice genetically deficient in important molecules often use compensatory defense mechanisms that rely on other redundant pathways. Thus, and more generally, it is conceivable that any genetic deficiency for specific inhibitory pathways is likely to alter the outcomes of specific therapies targeting these important pathways in immune defense and homeostasis.

While the genetic deficiency in PD-L1 versus therapeutic mAb blockade of PD-L1 in WT mice clearly results in different outcomes for $P y$ parasitemia and immune responses, our experiments using anti-LAG-3 mAb blockade raises an important point related to the underlying mechanisms of increased resistance to $P y$ infection. The Butler study reported significantly stronger $\mathrm{T}_{\mathrm{FH}}, \mathrm{GC}$ and plasmablast responses, as well as higher titers of $\mathrm{MSP}_{19}$ parasitespecific Abs in anti-PD-L1/LAG-3-treated WT mice compared to control groups. Whereas we did confirm enhanced $\mathrm{T}_{\mathrm{FH}}$ cell and GC responses in anti-PD-L1/LAG-3 treated WT mice, this resulted neither into higher parasite (MSP1 $\left.1_{19}\right)$-specific Ab titers, nor into a better ability to confer protection to sera-transferred recipient mice infected with $P y$. We extended these findings to anti-LAG-3 versus control isotype $\mathrm{Ab}$ treated $\mathrm{PD}-\mathrm{L1}^{-/-}$mice, suggesting that parasitespecific $\mathrm{Ab}$ responses are unlikely to account for the enhanced antiparasitic response that follows LAG-3 mAb blockade. While our serum transfer experiments were conducted according to the Butler study, i.e., single transfer of $150 \mu \mathrm{l}$ of pooled sera from convalescent mice (day 32) prior to $P y$ infection of recipient mice, most previous studies showing significant protection against malaria upon serum transfer, used $200 \mu \mathrm{l}$ and at least three serial transfers at the beginning of infection $(21,22)$. We also transferred sera isolated from mice at different time points post $P y$ infection (day 18, 32 and 72) following the rationale that, if Abs are indeed mediating an effective anti-parasite response, this effect should be even clearer at early time points of infection when the differences between antiLAG-3 and control isotype Ab treated mice are the greatest (day 18). Yet our results did not support such an interpretation. While we 
observe that sera from day 72 convalescent mice -a time point at which peak parasite specific Abs are produced (18)- conferred better protection to recipient mice compared to pre-immune sera, we did not find i) any significant differences in the ability to confer parasitespecific protection or ii) higher parasite-specific $\mathrm{Ab}$ titers in antiLAG-3 or anti-PD-L1/LAG-3 treated PD-L1 ${ }^{-/-}$or WT mice, respectively. Since we did not observe differences, we did not extend our sera analysis to potential differences in isotype switching among the $P y$-specific IgGs. Yet it is worth noting that previous work did report that $P y$-specific IgG2a Abs conferred or were associated with better protection, compared to other isotypes, presumably through the recognition of a similar set of $P y$ antigens (23-25). It is therefore conceivable that PD-L1 and/or LAG-3 blockade does lead to the production of a distinct set of IgG isotypes despite the lack of functional differences. Interestingly, in sera from Plasmodium falciparum (Pf)-infected children, higher IgG3 and to some extent IgG1 and IgG4 levels were associated with protective $P f$ antigens boosted upon RTS/S vaccination, while IgG2 correlated with increased malaria risk (26). Pf (AMA-1)-specific IgG1 and IgG3 Ab titers are also associated with immunity above a certain age (27), consistent with the notion that IgG isotypes, in addition to Ag specificity, are likely associated with parasite-specific humoral immunity.

We also note that our anti-LAG-3 treatment regimen was only 4 consecutive injections, compared to 7 in the Butler study. While it is possible that this accounts for some differences in the outcomes, the day 32 sera transfers conducted in this prior work seem unlikely to reflect fully the protective mechanisms at work during anti-LAG-3 treatment between day 9 and 18 post $P y$ infection. Taken together, we favor the interpretation that LAG-3 neutralization leads to improved control of parasitemia by rescuing functional effector $\mathrm{CD} 4^{+} \mathrm{T}$ cell responses, independent of parasite-specific $\mathrm{Ab}$ responses. A high proportion of activated proliferating (CD62L ${ }^{\text {lo }} \mathrm{CD} 44{ }^{\mathrm{hi}} \mathrm{Ki} 67^{+}$) Ag-specific (CD49d/ CD $11 \mathrm{a}^{+}$) effector $\left(\mathrm{T}_{\text {bet }}^{\text {hi }}\right) \mathrm{CD}^{+} \mathrm{T}$ cells are observed among LAG $-3^{+} \mathrm{CD}^{+} \mathrm{T}$ cells. We found that a greater frequency of these cells secrete effector cytokines (IFN $\gamma$, TNF $\alpha$, IL-2) in antiLAG-3-treated versus control mice. These effector cytokinesecreting $\mathrm{CD}^{+} \mathrm{T}$ cells may also promote the influx and activation of higher numbers of innate inflammatory cells, e.g., monocytes, macrophages and neutrophils, to the spleen where blood filtration and parasite clearance takes place $(28,29)$.

We provide strong evidence that while both $\mathrm{CD}^{+}$and $\mathrm{CD} 4^{+} \mathrm{T}$ cells express LAG-3 at the time of anti-LAG-3 treatment (day 7.5), and represent the major LAG-3-expressing cells during $P y$ infection (>80\%), LAG-3 blockade is most likely acting on $\mathrm{CD}^{+} \mathrm{T}$ cells to unleash specific key effector mechanisms that help induce a more effective anti-parasite immune response. Despite an extensive analysis of these antigen-experienced parasite-specific $\mathrm{CD} 4^{+}$ $\mathrm{T}$ cells across various time points post $P y$ infection (day 7.5, 17 and 36), along with high dimensional 26 color flow cytometry panels, $\mathrm{t}-\mathrm{SNE}$ and FlowSOM analysis of the $\mathrm{CD} 4^{+} \mathrm{T}$ cells in antiLAG-3 or control isotype-treated PD- $1^{-/-}$mice, we did not find any differences in $\mathrm{CD}^{+}{ }^{+} \mathrm{T}$ cell subsets. The proportion of activated and proliferating $\mathrm{CD}^{+} \mathrm{T}$ cells, and of $\mathrm{T}_{\text {bet }}^{+}$(Th1), $\mathrm{ICOS}^{+}, \mathrm{T}_{\mathrm{FH}}$ and $\mathrm{T}_{\mathrm{FR}}$ remained equivalent in all experimental groups, consistent with the lack of detectable differences in the humoral response. Since cytokine production by the $\mathrm{CD} 4^{+} \mathrm{T}$ cells upon in vitro restimulation was the only functional read out that we found significantly different, we propose that LAG-3 blockade is likely to act as a rapid and temporary boost of activated $\mathrm{CD} 4^{+} \mathrm{T}$ cells in this infection. Perhaps akin to this experimental situation is the antiPD-1 treatment in chronic virus-infected mice that re-invigorates exhausted $\mathrm{CD}^{+} \mathrm{T}$ cells, yet still fails to achieve long-term reprogramming of these cells (30).

Even though our data support a functional role for $\mathrm{CD} 4^{+} \mathrm{T}$ cells in effective anti-parasite immunity, the fibrinogen-like protein 1 (FGL-1) appears as a major ligand of LAG-3 that works independently of MHC-II, and inhibits T cell-mediated antitumor immunity (4). While it is unknown whether levels of FGL1 increase during malaria infection, an appealing hypothesis may be that FGL-1 contributes to inhibiting LAG-3 expressing subsets of T cells during infection, including $\mathrm{CD}^{+} \mathrm{T}$ cells. Along this hypothesis, we found a slightly delayed blood parasitemia clearance in anti-LAG-3-treated, $\mathrm{CD}^{+} \mathrm{T}$ cell-depleted PD-L1 ${ }^{-/}$ mice, and a mild increase in cytokines secreted after ex vivo stimulation of $\mathrm{CD}^{+}$T cells isolated from anti-LAG-3-treated $P y$ infected mice. Whereas we did find some modest differences, the lack of $\mathrm{CD}^{+} \mathrm{T}$ cells did not significantly affect the kinetics of blood parasitemia, consistent with prior studies using the same Py17XNL1.1 strain and selective depletion or genetic depletion of $\mathrm{CD}^{+} \mathrm{T}$ cells (31-33). Of note, however, another group using a more virulent strain of $P y, P y N L$, documented a key role for $\mathrm{CD}^{+} \mathrm{T}$ cells in the control of blood parasitemia, invoking both IFN $\gamma$ - and Fas-Ldependent protection mediated by the $\mathrm{CD} 8^{+} \mathrm{T}$ cells and macrophages $(34,35)$. The potential importance of $\mathrm{CD}^{+} \mathrm{T}$ cells during blood stage malaria, was also recently highlighted in $P y$ (17XNL1.1)-infected transgenic mice expressing the humanrestricted cytolytic effector molecule granulysin (GNLY) (36). Here, formal proof of concept that $\mathrm{GNLY}^{+} \mathrm{CD}^{+} \mathrm{T}$ cells, shown to recognize and kill $P$. vivax-infected $\mathrm{MHC}-\mathrm{I}^{+}$reticulocytes (iRetics) ex vivo (37), could also kill $\mathrm{MHC}-\mathrm{I}^{+} P y$-iRetics in this model (36). Other studies using the $P$. chabaudi murine model of infection that induces low chronic blood-parasitemia rebounds over 1-3 months post infection $(13,38)$, have also reported CD8 ${ }^{+}$ $\mathrm{T}$ cells, which express high cell-surface PD-1, to be essential in mediating effective blood stage parasite clearance during the chronic rebound phase and PD-1 blockade (13). Thus, while the above studies provide solid evidence supporting a role for $\mathrm{CD}^{+} \mathrm{T}$ cells during blood stage malaria, it is likely that this is accounted for by virulence features specific to the parasite strain such as its ability to infect reticulocytes ( $P$. vivax, $P$. yoelii) and cause chronic episodes (P. vivax, P. chabaudi).

In the case of $P y$ 17XNL1.1 infections, however, all studies including ours, consistently report a more prominent role for $\mathrm{CD} 4^{+} \mathrm{T}$ cells in the control of blood stage parasitemia $(8,31,32$, 38). Thus LAG-3 blockade most likely acts through unmasking CD4 interactions with MHC-II to promote higher secretion of effector cytokines and -possibly- more robust recruitment/ activation of innate effector cells. Even though we could only measure a limited impact of LAG-3/PD-L1 blockade on the immune response, the treatment significantly diminishes blood 
parasitemia ( $\sim 30 \%$ from day $\sim 12$ and on), which may be essential in limiting the excessive inflammation associated with severe malaria. The treatment also appears to be effective at relatively high blood parasitemia, which furthers its potential therapeutic value. Overall, these inhibitory pathways appear to slow down host clearance of the parasite in this non-lethal animal model of malaria, but additional studies of these pathways in a lethal model, that better represents infection outcomes in humans, will be needed to understand the clinical implications of targeting these pathways during natural infection.

\section{DATA AVAILABILITY STATEMENT}

The original contributions presented in the study are included in the article/Supplementary Material. Further inquiries can be directed to the corresponding author.

\section{ETHICS STATEMENT}

The animal study was reviewed and approved by The Institutional Animal Care and Use Committee of the Albert Einstein College of Medicine.

\section{AUTHOR CONTRIBUTIONS}

RF and LC designed, performed, and interpreted most experiments and contributed to figures and discussions. NZ and EG set up and conducted all Ab titer measurements. ES

\section{REFERENCES}

1. Page DB, Postow MA, Callahan MK, Allison JP, Wolchok JD. Immune modulation in cancer with antibodies. Annu Rev Med (2014) 65:185-202. doi: 10.1146/annurev-med-092012-112807

2. Keir ME, Butte MJ, Freeman GJ, Sharpe AH. PD-1 and its ligands in tolerance and immunity. Annu Rev Immunol (2008) 26:677-704. doi: 10.1146/ annurev.immunol.26.021607.090331

3. Sierro S, Romero P, Speiser DE. The CD4-like molecule LAG-3, biology and therapeutic applications. Expert Opin Ther Targets (2011) 15:91-101. doi: $10.1517 / 14712598.2011 .540563$

4. Wang J, Sanmamed MF, Datar I, Su TT, Ji L, Sun J, et al. Fibrinogen-like Protein 1 Is a Major Immune Inhibitory Ligand of LAG-3. Cell (2019) 176:334-347 e12. doi: 10.1016/j.cell.2018.11.010

5. Wherry EJ, Ha SJ, Kaech SM, Haining WN, Sarkar S, Kalia V, et al. Molecular signature of CD8+ T cell exhaustion during chronic viral infection. Immunity (2007) 27:670-84. doi: 10.1016/j.immuni.2007.09.006

6. Barber DL, Wherry EJ, Masopust D, Zhu B, Allison JP, Sharpe AH, et al. Restoring function in exhausted CD8 T cells during chronic viral infection. Nature (2006) 439:682-7. doi: 10.1038/nature04444

7. Wykes MN, Horne-Debets JM, Leow CY, Karunarathne DS. Malaria drives T cells to exhaustion. Front Microbiol (2014) 5:249. doi: 10.3389/fmicb. 2014.00249

8. Butler NS, Moebius J, Pewe LL, Traore B, Doumbo OK, Tygrett LT, et al. Therapeutic blockade of PD-L1 and LAG-3 rapidly clears established blood-stage Plasmodium infection. Nat Immunol (2011) 13:188-95. doi: 10.1038/ni.2180

9. Illingworth J, Butler NS, Roetynck S, Mwacharo J, Pierce SK, Bejon P, et al. Chronic exposure to Plasmodium falciparum is associated with phenotypic contributed to early experiments. SC contributed to the design of high dimensional flow cytometry panels. JD contributed to discussions and editing of the paper. GL designed experiments with RF and LC, assembled and edited figures and wrote the paper with critical reading by all authors. All authors contributed to the article and approved the submitted version.

\section{FUNDING}

This work was funded by the National Institute of Health Grants (NIH/NIAID) AI103666 and AI128735 and Hirschl Caulier Award to GL. RF was supported by the NIH BETTR IRACDA training grant K12GM102779. LC received fellowships from Foundation Bettencourt-Schuller and the American Association of Immunology (AAI). ES and SC were supported by NIH training Grant T32A170117. EG was supported by NIH PREP R25GM104547.

\section{ACKNOWLEDGMENTS}

We thank the Einstein FACS core facility.

\section{SUPPLEMENTARY MATERIAL}

The Supplementary Material for this article can be found online at: https://www.frontiersin.org/articles/10.3389/fimmu.2020. 576743/full\#supplementary-material

evidence of B and T cell exhaustion. J Immunol (2013) 190:1038-47. doi: $10.4049 /$ jimmunol.1202438

10. Subramaniam KS, Spaulding E, Ivan E, Mutimura E, Kim RS, Liu X, et al. The T-Cell Inhibitory Molecule Butyrophilin-Like 2 Is Up-regulated in Mild Plasmodium falciparum Infection and Is Protective During Experimental Cerebral Malaria. J Infect Dis (2015) 212:1322-31. doi: 10.1093/infdis/jiv217

11. Portugal S, Tipton CM, Sohn H, Kone Y, Wang J, Li S, et al. Malariaassociated atypical memory B cells exhibit markedly reduced B cell receptor signaling and effector function. eLife (2015) 4:1-21. doi: 10.7554/eLife.07218

12. Chandele A, Mukerjee P, Das G, Ahmed R, Chauhan VS. Phenotypic and functional profiling of malaria-induced CD8 and CD4 T cells during bloodstage infection with Plasmodium yoelii. Immunology (2011) 132:273-86. doi: 10.1111/j.1365-2567.2010.03363.x

13. Horne-Debets JM, Faleiro R, Karunarathne DS, Liu XQ, Lineburg KE, Poh CM, et al. PD-1 dependent exhaustion of CD8+ T cells drives chronic malaria. Cell Rep (2013) 5:1204-13. doi: 10.1016/j.celrep.2013.11.002

14. Karunarathne DS, Horne-Debets JM, Huang JX, Faleiro R, Leow CY, Amante F, et al. Programmed Death-1 Ligand 2-Mediated Regulation of the PD-L1 to PD-1 Axis Is Essential for Establishing CD4(+) T Cell Immunity. Immunity (2016) 45:333-45. doi: 10.1016/j.immuni.2016.07.017

15. von der Weid T, Honarvar N, Langhorne J. Gene-targeted mice lacking B cells are unable to eliminate a blood stage malaria infection. J Immunol (1996) 156:2510-6.

16. Allman D, Pillai S. Peripheral B cell subsets. Curr Opin Immunol (2008) 20:149-57. doi: 10.1016/j.coi.2008.03.014

17. Crotty S. Follicular helper CD4 T cells (TFH). Annu Rev Immunol (2011) 29:621-63. doi: 10.1146/annurev-immunol-031210-101400

18. Akter J, Khoury DS, Aogo R, Lansink LIM, SheelaNair A, Thomas BS, et al. Plasmodium-specific antibodies block in vivo parasite growth without 
clearing infected red blood cells. PloS Pathog (2019) 15:e1007599. doi: 10.1371/journal.ppat.1007599

19. Gerlach C, Moseman EA, Loughhead SM, Alvarez D, Zwijnenburg AJ, Waanders L, et al. The Chemokine Receptor CX3CR1 Defines Three Antigen-Experienced CD8 T Cell Subsets with Distinct Roles in Immune Surveillance and Homeostasis. Immunity (2016) 45:1270-84. doi: 10.1016/ j.immuni.2016.10.018

20. Huang RY, Francois A, McGray AR, Miliotto A, Odunsi K. Compensatory upregulation of PD-1, LAG-3, and CTLA-4 limits the efficacy of single-agent checkpoint blockade in metastatic ovarian cancer. Oncoimmunology (2017) 6: e1249561. doi: 10.1080/2162402X.2016.1249561

21. Rotman HL, Daly TM, Clynes R, Long CA. Fc receptors are not required for antibody-mediated protection against lethal malaria challenge in a mouse model. J Immunol (1998) 161:1908-12.

22. Su Z, Stevenson MM. IL-12 is required for antibody-mediated protective immunity against blood-stage Plasmodium chabaudi AS malaria infection in mice. J Immunol (2002) 168:1348-55. doi: 10.4049/jimmunol.168.3.1348

23. White WI, Evans CB, Taylor DW. Antimalarial antibodies of the immunoglobulin G2a isotype modulate parasitemias in mice infected with Plasmodium yoelii. Infect Immun (1991) 59:3547-54. doi: 10.1128/ IAI.59.10.3547-3554.1991

24. Langhorne J, Evans CB, Asofsky R, Taylor DW. Immunoglobulin isotype distribution of malaria-specific antibodies produced during infection with Plasmodium chabaudi adami and Plasmodium yoelii. Cell Immunol (1984) 87:452-61. doi: 10.1016/0008-8749(84)90014-5

25. Smith EC, Taylor-Robinson AW. Parasite-specific immunoglobulin isotypes during lethal and non-lethal murine malaria infections. Parasitol Res (2003) 89:26-33. doi: 10.1007/s00436-002-0687-3

26. Dobano C, Santano R, Vidal M, Jimenez A, Jairoce C, Ubillos I, et al. Differential Patterns of IgG Subclass Responses to Plasmodium falciparum Antigens in Relation to Malaria Protection and RTS,S Vaccination. Front Immunol (2019) 10:439. doi: 10.3389/fimmu.2019.00439

27. Stanisic DI, Fowkes FJ, Koinari M, Javati S, Lin E, Kiniboro B, et al. Acquisition of antibodies against Plasmodium falciparum merozoites and malaria immunity in young children and the influence of age, force of infection, and magnitude of response. Infect Immun (2015) 83:646-60. doi: 10.1128/IAI.02398-14

28. Sponaas AM, Freitas do Rosario AP, Voisine C, Mastelic B, Thompson J, Koernig S, et al. Migrating monocytes recruited to the spleen play an important role in control of blood stage malaria. Blood (2009) 114:5522-31. doi: 10.1182/blood-2009-04-217489

29. Aitken EH, Alemu A, Rogerson SJ. Neutrophils and Malaria. Front Immunol (2018) 9:3005. doi: 10.3389/fimmu.2018.03005
30. Pauken KE, Sammons MA, Odorizzi PM, Manne S, Godec J, Khan O, et al. Epigenetic stability of exhausted $\mathrm{T}$ cells limits durability of reinvigoration by PD-1 blockade. Science (2016) 354:1160-5. doi: 10.1126/science.aaf2807

31. Suss G, Eichmann K, Kury E, Linke A, Langhorne J. Roles of CD4- and CD8bearing $\mathrm{T}$ lymphocytes in the immune response to the erythrocytic stages of Plasmodium chabaudi. Infect Immun (1988) 56:3081-8. doi: 10.1128/ IAI.56.12.3081-3088.1988

32. van der Heyde HC, Manning DD, Roopenian DC, Weidanz WP. Resolution of blood-stage malarial infections in CD8+ cell-deficient beta 2-m0/0 mice. J Immunol (1993) 151:3187-91.

33. Vinetz JM, Kumar S, Good MF, Fowlkes BJ, Berzofsky JA, Miller LH. Adoptive transfer of CD8+ T cells from immune animals does not transfer immunity to blood stage Plasmodium yoelii malaria. J Immunol (1990) 144:1069-74.

34. Imai $\mathrm{T}$, Shen J, Chou B, Duan X, Tu L, Tetsutani K, et al. Involvement of $\mathrm{CD} 8+\mathrm{T}$ cells in protective immunity against murine blood-stage infection with Plasmodium yoelii 17XL strain. Eur J Immunol (2010) 40:1053-61. doi: 10.1002/eji.200939525

35. Imai T, Ishida H, Suzue K, Taniguchi T, Okada H, Shimokawa C, et al. Cytotoxic activities of CD8(+) T cells collaborate with macrophages to protect against bloodstage murine malaria. eLife (2015) 4:1-22. doi: 10.7554/eLife.04232

36. Hojo-Souza NS, de Azevedo PO, de Castro JT, Teixeira-Carvalho A, Lieberman J, Junqueira C, et al. Contributions of IFN-gamma and granulysin to the clearance of Plasmodium yoelii blood stage. PloS Pathog (2020) 16:e1008840. doi: 10.1371/journal.ppat.1008840

37. Junqueira C, Barbosa CRR, Costa PAC, Teixeira-Carvalho A, Castro G, Sen Santara S, et al. Cytotoxic CD8(+) T cells recognize and kill Plasmodium vivax-infected reticulocytes. Nat Med (2018) 24:1330-6. doi: 10.1038/s41591018-0117-4

38. Podoba JE, Stevenson MM. CD4+ and CD8+ T lymphocytes both contribute to acquired immunity to blood-stage Plasmodium chabaudi AS. Infect Immun (1991) 59:51-8. doi: 10.1128/IAI.59.1.51-58.1991

Conflict of Interest: The authors declare that the research was conducted in the absence of any commercial or financial relationships that could be construed as a potential conflict of interest.

Copyright $\odot 2021$ Furtado, Chorro, Zimmerman, Guillen, Spaulding, Chin, Daily and Lauvau. This is an open-access article distributed under the terms of the Creative Commons Attribution License (CC BY). The use, distribution or reproduction in other forums is permitted, provided the original author(s) and the copyright owner(s) are credited and that the original publication in this journal is cited, in accordance with accepted academic practice. No use, distribution or reproduction is permitted which does not comply with these terms. 